This manuscript is a preprint and has been submitted for publication in Journal of Geophysical Research: Atmospheres. Please note that, despite having undergone peer-review, the manuscript has yet to be formally accepted for publication. Subsequent versions of this manuscript may have slightly different content. If accepted, the final version of this manuscript will be available via the 'Peer-reviewed Publication DOI' link on the right-hand side of this webpage. Please feel free to contact any of the authors; we welcome feedback. 


\title{
Effects of groundwater pumping on ground surface temperature: A regional modeling study in the North China Plain
}

\author{
Chen Yang 1,2,3, Hong-Yi Li ${ }^{3}$, Yilin Fang 4 , Chixiao Cui ${ }^{5}$, Tianye Wang6,7, Chunmiao \\ Zheng $^{1,2}$, L. Ruby Leung ${ }^{4}$, Reed M. Maxwell ${ }^{8}$, You-Kuan Zhang1,2*, Xiaofan Yang9,10*
}

${ }^{1}$ Guangdong Provincial Key Laboratory of Soil and Groundwater Pollution Control, School of Environmental Science and Engineering, Southern University of Science and Technology, Shenzhen 518055, China.

${ }^{2}$ State Environmental Protection Key Laboratory of Integrated Surface Water-Groundwater Pollution Control, School of Environmental Science and Engineering, Southern University of Science and Technology, Shenzhen 518055, China.

${ }^{3}$ Cullen College of Engineering, University of Houston, Houston, TX 77204, USA.

${ }^{4}$ Pacific Northwest National Laboratory, Richland, WA 99354, USA.

${ }^{5}$ Taihu Lake Laboratory Ecosystem Research Station, State Key Laboratory of Lake Science and Environment, Nanjing Institute of Geography and Limnology, Chinese Academy of Sciences, Nanjing 21008, China.

${ }^{6}$ Key Laboratory of Water Cycle and Related Land Surface Processes, Institute of Geographic Sciences and Natural Resources Research, Chinese Academy of Sciences, Beijing 100101, China. ${ }^{7}$ University of Chinese Academy of Sciences, Beijing 100049, China.

${ }^{8}$ Department of Geology and Geological Engineering, Colorado School of Mines, Golden, CO 80401, USA.

${ }^{9}$ State Key Laboratory of Earth Surface Processes and Resource Ecology, Faculty of Geographical Science, Beijing Normal University, Beijing 100875, China.

${ }^{10}$ Beijing Computational Science Research Center, Beijing 100195, China.

Corresponding author:

Xiaofan Yang (xfyang@bnu.edu.cn); You-Kuan Zhang (zhangyk@ sustech.edu.cn)

\section{Key Points}

- Effects of groundwater pumping on ground surface temperature (GST) in the North China Plain is investigated using an integrated model.

- Groundwater pumping increases the annual average ground surface temperature and results in hotter summers and colder winters.

- Effects of groundwater pumping on GST may last for 20 years, with larger effect in the beginning due to nonlinear response. 


\section{Abstract}

Over-exploitation of groundwater (GW) in the North China Plain (NCP) since the 1960s has many environmental consequences. However, understanding of the dominant mechanisms remains

39 limited, particularly at the regional scale. In this study, the coupled ParFlow.CLM model 40 representing subsurface and land-surface processes and their interactions was applied in the NCP 41 at high spatio-temporal resolutions. The model was validated using the water and energy fluxes 42 reported in previous studies and from the JRA-55 reanalysis. Numerical experiments were designed to examine the relative impacts of GW pumping and irrigation on the ground surface

44 temperature (GST). Results showed significant effects of GW pumping on GST in the NCP. 45 Generally, the subsurface acts as a buffer to temporal variations in heat fluxes at the land-surface, 46 but long-term pumping can gradually weaken this buffer, resulting in increases in the spatio47 temporal variability of GST, as exemplified by hotter summers and colder winters. Considering 48 that changes of water table depth (WTD) can significantly affect land surface heat fluxes when 49 WTD ranges roughly between 1-10 m, the $0.5 \mathrm{~m} /$ year increase of WTD simulated by the model 50 due to pumping can continue to increase the average WTD and hence, GST, for about 20 years 51 from the pre-pumping WTD in the NCP, before the WTD exceeds $10 \mathrm{~m}$. The increase of GST is 52 expected to be faster initially and gradually slow down due to the nonlinear increase of GST with 53 WTD. The findings from this study in the NCP may also have implications for other regions with 54 GW depletion.

55 Keywords: The North China Plain, Groundwater pumping, Ground surface temperature, 56 Integrated modeling, ParFlow.CLM 


\section{Introduction}

Ground surface temperature (GST) and soil temperature (ST) have important influence on terristrial processes such as ecosystem functions, surface-subsurface interactions, and landatmosphere interactions, with implications for how the terrestrial system responds to climate change [H Zhang et al., 2016]. For example, ST controls the growth of vegetation, which is extremely sensitive to temperature, so it is a major factor influencing crop yield in agricultural regions [H Zhang et al., 2016]. The increase in ST has accelerated soil respiration, with a $20 \%$ increase in soil respiration corresponding to a release of about 14-20 PgC/yr soil carbon, which is 2-3 times the amount of carbon released from fossil fuel and land use change (7 PgC/yr) [Davidson et al., 2006; Lloyd and Taylor, 1994].

$\mathrm{GW}$ is an important source of fresh water in many populated regions such as the North China Plain (NCP), which is the political, economic, and agricultural center of China. Over-exploitation of GW in the NCP since the 1960s mainly for irrigation has many environmental consequences, such as river deterioration, land subsidence, and seawater intrusion [C M Liu et al., 2001]. Water table depth (WTD) in most places of the NCP is now more than tens of meters, much deeper than 1-3 m during the 1960s, with some regions such as Beijing, Shijiazhuang, and Cangzhou showing WTD of more than one hundred meters [Cao et al., 2013]. Meanwhile, with climate change [Kang and Eltahir, 2018], the annual average air temperature in the $\mathrm{NCP}$ has increased by $0.23{ }^{\circ} \mathrm{C}$ per decade, which is slightly higher than the global average during the same period [A et al., 2016]. The rising air temperature could lead to the changes in GST [Pollack et al., 2005].

Figure 1 shows the variations of GST and WTD in the NCP for the last 40 years. With increasing trends in both GST and WTD, an important question is whether the GW withdrawal may have contributed to the increasing GST, although the latter has generally been attributed to the increasing air temperature [Pollack et al., 2005; H Zhang et al., 2016; T Zhang et al., 2001]. Recent studies addressing the important role of GW in the subsurface-land-surface-atmosphere system [Keune et al., 2016; R. M. Maxwell and Condon, 2016; Taylor et al., 2013] noted the important control of GW on soil moisture that governs the land surface energy fluxes, with subsequent influence on local weather and climate through land-atmosphere interactions [Ferguson and Maxwell, 2012]. However, few studies have looked at the impact of human activities such as GW pumping or irrigation on GST at the regional scale. During the rapid socioeconomic development over the NCP in the past few decades, GW pumping has been 

al., 2001].

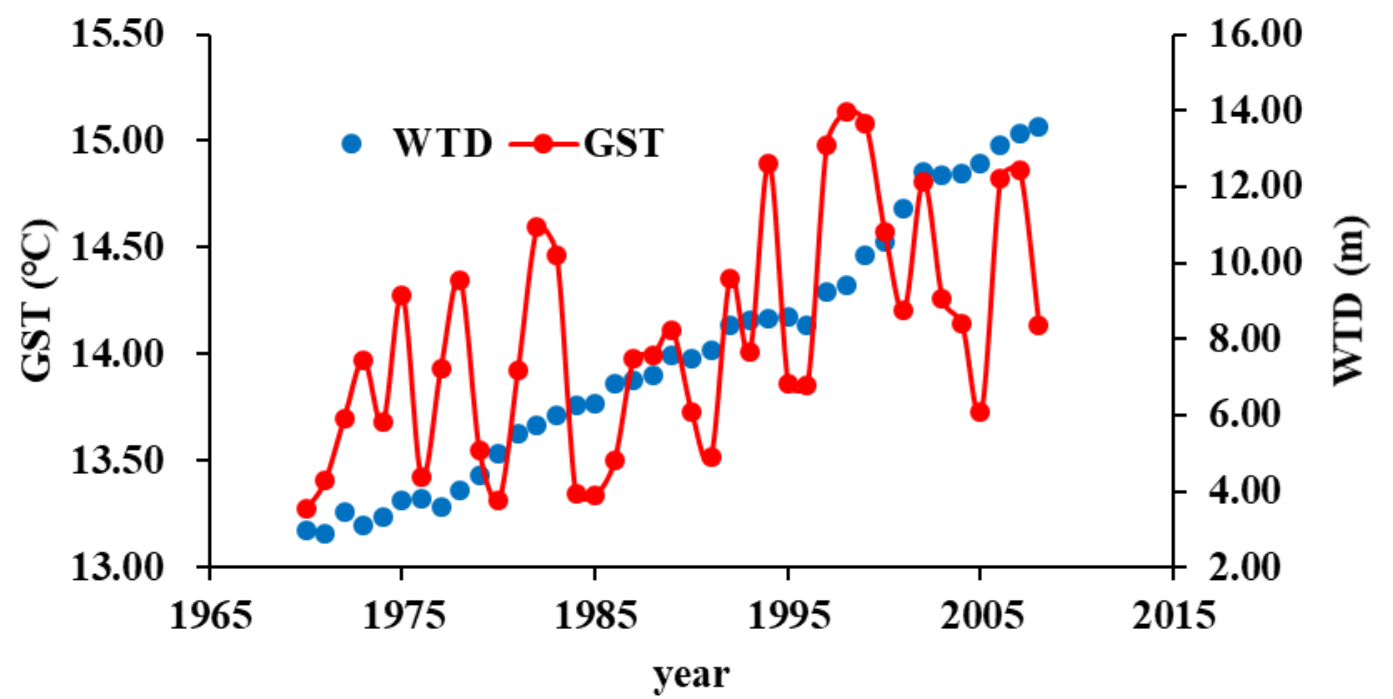

Figure 1. Yearly variations in GST and WTD from 1970 to 2008 in the NCP. GST is at the center of the NCP from JRA-55 reanalysis data [Harada et al., 2016; Kobayashi et al., 2015]; while WTD is the regional average from a previous modeling study [Cao et al., 2013].

GW movements and pumping in the NCP has been examined by numerous studies using mostly groundwater models such as MODFLOW [Cao et al., 2013; Cui et al., 2009; Hu et al., 2010; Jia and Liu, 2002; J Liu et al., 2008; Wang et al., 2008; Xue et al., 2010; X Zhang, 2007; X Zhang et al., 2008]. The models were usually applied at local scale with a focus on estimating the water budget, with limited attention to groundwater processes and feedbacks to energy related processes. Nevertheless, Zou et al. [2015] studied the effects of GW exploitation on land surface processes at the Haihe River Basin located in the NCP. The GW component was conceptualized as a water bucket and the related calculation was based on simple water budget. The oversimplification of GW dynamics in land surface models has been recognized in the last decade, highlighting the lack of representations of lateral GW flow and heat transport [Bisht et al., 2018; Fang et al., 2017; Zeng et al., 2018], which may limit our ability to model not only land surface processes but also land-atmosphere interactions.

Recent progress has been made in development of coupled land surface-subsurface models [Alkhaier et al., 2012; Davison et al., 2015; R. M. Maxwell et al., 2011; R. M. Maxwell and Miller, 2005; Rahman et al., 2015]. In addition, regional or global maps of hydraulic parameters for soils and deep aquifers have become available [Gleeson et al., 2014; Gleeson et al., 2011; Y G Zhang 
et al., 2018] to facilitate integrated modeling at large scales, using models such as ParFlow.CLM over most of the continental US [R. M. Maxwell and Condon, 2016] and TerrSysMP over the European CORDEX domain [Keune et al., 2016]. Using an integrated model ParFlow.CLM in the medium-sized Little Washita Basin, Ferguson and Maxwell [2011; 2012] studied the effect of irrigation and pumping on land surface water and energy fluxes and compared this effect with that of climate change. Subsequently, in the same basin, Condon and Maxwell [2014a; 2014b] studied the system dynamics with a spatio-temporal framework under managed irrigation by coupling ParFlow.CLM with an additional Water Allocation Module. Most recently, Condon and Maxwell [2019] studied the sentivity of evapotranspiration and streamflow to groundwater depletion over most of the continental US (CONUS). However, few studies have analyzed the regional GST dynamics under GW pumping using intergrated modeling approach.

The overarching goal of this study is to explore the possible effects of GW pumping on land surface processes, especially GST, in the NCP using ParFlow.CLM. The model was first set up over the NCP, then used to study the effects of GW pumping and both pumping and irrigation $(\mathrm{P} \& \mathrm{I})$ on water and energy related processes, with possible effects on the warming trend in the NCP. In what follows, we introduced the modeling experiments based on ParFlow.CLM and evaluated the baseline scenario by comparing the simulated WTD, GST, sensible heat flux $(\mathrm{H})$, and latent heat flux (LE) with results from previous studies and the JRA-55 reanalysis data products. These variables were selected due to their important roles in land surface-subsurface interactions. Different scenarios were also compared to characterize uncertainties in the modeling. Then the effects of pumping and P\&I on WTD and GST were explored. Finally, implications and limitations of this study were summarized.

\section{Integrated modeling in the NCP}

\subsection{Model description: ParFlow.CLM}

ParFlow.CLM [R. M. Maxwell and Miller, 2005] is an open source, integrated land surface and subsurface model (https://github.com/parflow/parflow) developed by coupling a modified version of the Common Land Model (CLM 3.0) [Dai et al., 2003; Ferguson et al., 2016; Jefferson and Maxwell, 2015; Jefferson et al., 2017; R. M. Maxwell and Condon, 2016] and an integrated surfacesubsurface flow model (ParFlow) [Ashby and Falgout, 1996; Jones and Woodward, 2001; Kollet and Maxwell, 2006]. ParFlow represents the variably saturated subsurface flow by solving the 
three-dimensional Richards' equation and integrates it with the overland flow by solving the twodemensional kinematic wave equation and a free-surface boundary condition [Kollet and Maxwell, 2006]. Replacement of the original one-dimensional vertical flow in CLM by ParFlow overcomes both the shortcoming of the lower flow boundary (e.g., the free drainage) and the limitation in simulating lateral subsurface flow in CLM [Keune et al., 2016; R. M. Maxwell and Miller, 2005]. At the same time, coupling of ParFlow with CLM improves the simple top boundary used in traditional subsurface flow model like ParFlow, in which snow, surface runoff, soil heating, and root-zone uptake processes are oversimplified or neglected [R. M. Maxwell and Miller, 2005]. Therefore, ParFlow.CLM can capture more realistic water-energy interactions in the subsurfaceland-surface system. The parallel computing capability and terrain following grid in ParFlow make it possible for ParFlow.CLM to be applied at large scale [Condon and Maxwell, 2014a]. More details on ParFlow.CLM can be found in many previous studies [Kollet and Maxwell, 2008; R. M. Maxwell and Miller, 2005]. ParFlow.CLM has been applied to more than a dozen watersheds around the world including the Big Thompson (CO), Klamath (OR), Little Washita (OK), Rur (Germany), San Joaquin (CA), Sante Fe (FL), Chesapeake (MD) and Skjern (Denmark) catchments [R. M. Maxwell and Condon, 2016], but it has not been applied and evaluated in the NCP before.

\subsection{Modeling domain}

The modeling domain $\left(34.45^{\circ} \mathrm{N}-41.00^{\circ} \mathrm{N}, 112.73^{\circ} \mathrm{E}-117.27^{\circ} \mathrm{E}\right)$ in this study is shown in Figure 2. The total area is about $467,274 \mathrm{~km}^{2}$, covering the Beijing Municipality, part of the Tianjing Municipality, and part of the Heibei, Henan, and Shandong Provinces (Figure 2a). The elevation in the study domain ranges from about $3000 \mathrm{~m}$ in the northwest Taihang Mountain to near the sea level in the east near the Bohai Sea (Figure 2b, Bohai Sea not shown). The current modeling domain was mostly adopted from the commonly defined NCP region [Cao et al., 2014; Cao et al., 2013; Qin et al., 2013] but slightly modified to simplify the implementation in ParFlow.CLM by using the smallest rectangle to cover the largest area of the NCP. The most active pumping areas, along the Taihang Mountain from Shijiazhuang to Beijing, are well located in the center of the modeling domain, so the boundary effect on the simulation results should be negligible due to the size of the buffer zone [Keune et al., 2016]. Since boundary conditions are not specified at the subsurface topographic boundaries, a rectangular domain was used to move the boundaries away from the study region of interest. Meteorological records showed that, from 
1771980 to 2011 , the mean annual precipitation and air temperature were $525 \mathrm{~mm}$ and $13.1^{\circ} \mathrm{C}$, 178 respectively [Pei et al., 2015].
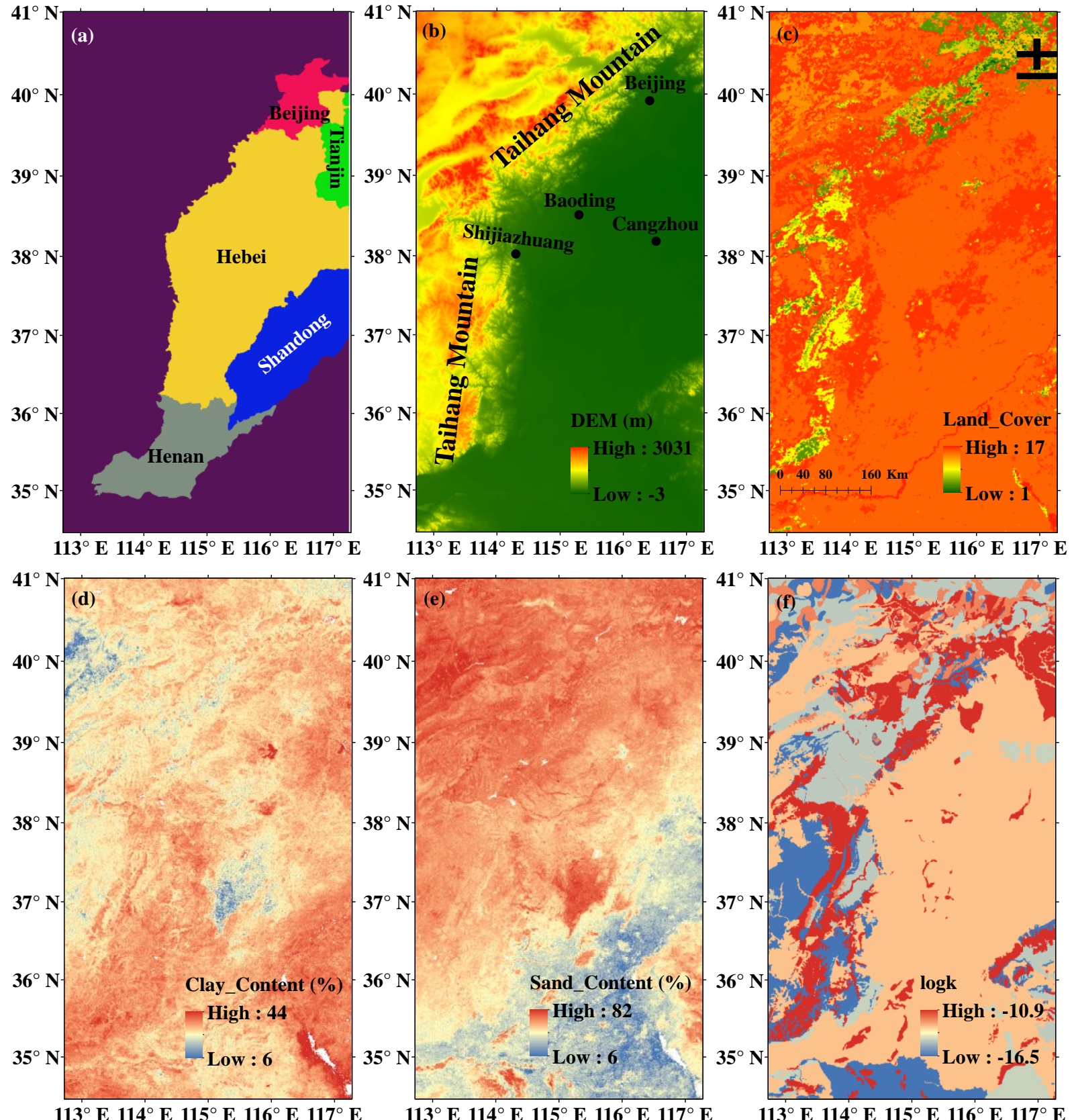

Figure 2. Administrative regions (a), topography (b), land cover (c), clay content of the surface soil (d), sand content of the surface soil (e), and logarithmic permeability of the deep aquifer (f) in the NCP modeling domain. 1-17 in the land cover subpanel corresponds to surface types defined by the 
High resolution is necessary to model the effects of well pumping. The cone of depression with WTD increasing from the edge to the center would be averaged to the same WTD if large grid cells are used, which may influence modeling of land surface energy variations that are dependent on the WTD [Taylor et al., 2013]. The subsurface in the study region was divided into $439 \times 799$ grid cells in the horizontal direction with a resolution of about $1 \mathrm{~km}$. This resolution is higher than the $2 \mathrm{~km}$ resolution used in previous regional modeling of the NCP [Cao et al., 2013; Qin et al., 2013]. With the terrain following grid, the subsurface was divided into 5 layers in the vertical direction. The thickness of the layers is $0.1,0.3,0.6,1$ and $100 \mathrm{~m}$ from top to bottom. Thus, the total number of grid cells in the modeling domain is $1,753,805$. The setting of vertical thickness is reasonable since the subsurface in the NCP is mainly composed of shallow and deep aquifer groups [Cao et al., 2013], which are relatively independent in terms of hydraulic connections [Gao, 2008]. The shallow aquifer group is $160 \mathrm{~m}$ deep on average [Cao et al., 2013], coinciding with the total thickness of the five layers used in the current study. Only the shallow aquifer group was modeled in this study since it is heavily disturbed by human activities (i.e., pumping and irrigation). This configuration is also consistent with those used in previous studies that have presented good results in CONUS [R. M. Maxwell and Condon, 2016; R. M. Maxwell et al., 2015; R. M. Maxwell et al., 2016].

\subsection{Data descriptions}

Topography in the NCP (Figure 2b) was described by the Digital Elevation Model (DEM) of $90 \mathrm{~m}$ resolution from the Shuttle Radar Topography Mission [Rabus et al., 2003]. Topographic slopes $\left(S_{x}\right.$ and $\left.S_{y}\right)$ were calculated based on the DEM and then adjusted by the watershed analysis tool in the GRASS Geographic Information System (GIS). The slopes were further modified by the parking lot tests and by the subsequent spin-up processes to ensure connectivity of the streams. Land cover data (Figure 2c) following the classification of the International Geosphere-Biosphere Program (IGBP) from the Global Land Cover Characterization (GLCC) database were downloaded from the USGS website (https://www.usgs.gov/centers/eros). Soil texture and hydraulic parameters (Figures 2d and 2e) in the top 4 layers were from a newly developed global soil map of $1 \mathrm{~km}$ resolution [Y G Zhang et al., 2018]. Permeability of the bottom layer (Figure 2f) was from Gleeson et al. [2014] with higher resolution than Gleeson et al. [2011]. Meteorological forcing data were obtained from the Japanese 55-year Reanalysis project (JRA-55). The forcing data were interpolated to the modeling grid. The 3-hourly forcing data were also linearly 
218 interpolated to hourly resolution. All the input data were re-projected to the same world Mercator

219 projected coordinate system and resampled, if necessary, to the same $1 \mathrm{~km}$ resolution.

\subsection{Boundary and initial conditions}

We used a free-surface overland flow boundary condition for the land surface and no-flow 222 boundary condition for all other boundaries. No-flow assumption for the lateral and bottom boundaries is reasonable since the buffer zone around the pumping area is large enough, and the shallow aquifer group in the NCP is hydraulically independent from the deep aquifers. For the subsurface (i.e., the ParFlow model), a constant infiltration of $1 \times 10^{-4} \mathrm{~m} /$ hour equivalent to the annual precipitation in the NCP and an initial condition of water table at $2 \mathrm{~m}$ below the land surface were set. The ParFlow model was spun up until the spatial distribution pattern of pressure head was in quasi-equilibrium. Then the coupled ParFlow.CLM model was spun up for another 2 years to achieve dynamic equilibrium. After the model spin-up, one-year simulations were performed for scenarios 1-5, and two more years were simulated for scenarios 6-7 for the pumping and irrigation experiments (Section 2.6). Forcing data in 1970 was used to represent the predevelopment condition since the extensive GW pumping began in the 1970s. An hourly time step was used in the one-year and two-year simulations producing daily output for analysis.

\subsection{Scenario setup}

The model configuration described above used the best publicly available data and serves as the baseline (scenario 1) in this study. The most uncertain aspects of the modeling are the subsurface permeabilities of soil and aquifer and the atmospheric forcing. Therefore, four

238 additional scenarios were setup by considering different combinations of meteorological forcing and subsurface heterogeneity (Table 1). 2D forcing refers to the spatially variable forcing while

240 1D forcing was defined at the center of the modeling domain and applied to the whole area. 241 Heterogeneous permeabilities were from Zhang et al. [2018] in the top soil and from Gleeson et 242 al. [2014] in the deep aquifer. "Homogeneous" refers to the uniform subsurface with a hydraulic 243 conductivity of $0.6958 \mathrm{~m} /$ hour, which is the geometric mean of the hydraulic conductivities in the 244 shallow aquifers of the NCP from Cao et al. [2013]. In scenario 5, anisotropy was also considered using a ratio of horizontal to vertical hydraulic conductivity of 10000 [Cao et al., 2013].

246 Comparison of the scenarios allows the effects of subsurface properties and meteorological forcing 247 on the regional water and energy processes to be better characterized. 
After the model was evaluated based on scenarios 1-5, two more scenarios 6 and 7 (Table 1) with pumping and P\&I were simulated based on the setting of scenario 1. Groundwater pumping information in the NCP for year 2001 [ $L i, 2013]$ was used and summarized in Table 2. This information represents the pumping intensity around year 2000 in the NCP. More details about the spatial and temporal variations of pumping in the NCP can be considered in future studies. In this study, groundwater pumping was only conducted in the NCP, i.e., outside the purple area (Figure 2a). All the agricultural water in Table 2 was assumed to be for irrigation only in this study. Irrigation was conducted by adding agricultural water to precipitation in the forcing data. In scenario 6, additional quadruple, double, half, and one quarter of the pumping rates were also considered. Increasing rates represent the increasing groundwater demand in the future, while decreasing rates represent the possible effect of smart water management or hydraulic projects, such as the south-to-north water transfer (SNWT) project in the NCP.

Table 1. Scenarios in the subsurface-land-surface modeling in the NCP

\begin{tabular}{|c|c|c|c|c|}
\hline Scenario & $\begin{array}{c}\text { Meteorological } \\
\text { Forcing }\end{array}$ & Permeability & Pumping & Irrigation \\
\hline $\begin{array}{c}1 \\
\text { (Baseline) }\end{array}$ & 2D & Heterogeneous & No & No \\
\hline 2 & 2D & Homogeneous & No & No \\
\hline 3 & 1D & Heterogeneous & No & No \\
\hline 4 & 1D & Homogeneous & No & No \\
\hline 5 & 2D & $\begin{array}{c}\text { Heterogeneous and } \\
\text { anisotropy }\end{array}$ & No & No \\
\hline 6 & 2D & Heterogeneous & Yes & Yes \\
\hline 7 & 2D & Heterogeneous & Yes & \\
\hline
\end{tabular}

Table 2. Groundwater pumping in shallow aquifers in the NCP

\begin{tabular}{|c|c|c|c|c|}
\hline $\begin{array}{c}\text { Administrative } \\
\text { Regions }\end{array}$ & $\begin{array}{c}\text { Total Pumping } \\
\left(\mathbf{1 0}^{\mathbf{8}} \mathbf{~ m}^{\mathbf{3}} \mathbf{y e a r}\right)\end{array}$ & $\begin{array}{c}\text { Area } \\
\left(\mathbf{1 0}^{\mathbf{4}} \mathbf{k m}^{\mathbf{2}}\right)\end{array}$ & $\begin{array}{c}\text { Pumping Rate } \\
(\mathbf{m} / \mathbf{h o u r})\end{array}$ & $\begin{array}{c}\text { Agricultural Water } \\
\left(\mathbf{1 0}^{\mathbf{8}} \mathbf{~ \mathbf { m } ^ { 3 }} / \mathbf{y e a r}\right)\end{array}$ \\
\hline Beijing & 26.44 & 1.04 & $2.89 \times 10^{-5}$ & 13.38 \\
\hline Tianjin & 1.06 & 1.76 & $6.87 \times 10^{-7}$ & 0.99 \\
\hline Hebei & 118.53 & 11.41 & $1.19 \times 10^{-5}$ & 99.81 \\
\hline Henan & 28.04 & 2.63 & $1.22 \times 10^{-5}$ & 23.36 \\
\hline Shandong & 15.93 & 4.79 & $3.79 \times 10^{-6}$ & 10.10 \\
\hline
\end{tabular}




\section{3. Results and Discussion}

\section{3.1. Model evaluation}

265

266

267

268

269

270

271

272

273

274

275

276

277

278

279

280

281

282

283

284

285

286

287

288

\subsubsection{Water table depth}

The simulated annual averaged WTD in 1970 in the baseline is shown in Figure 3a. Simulated WTD is generally $1 \mathrm{~m}$ in the plain area but reaches more than $60 \mathrm{~m}$ in the mountain areas. The WTD in the plain area of the NCP during predevelopment was estimated at 0-3 $\mathrm{m}$ [Cao et al., 2013; Fei et al., 2009]. Thus, the simulated WTD is within the range of the predevelopment condition. Compared to scenario 2 (Figure 3b), the WTD is more controlled by the DEM for a homogeneous subsurface but it is adjusted by the subsurface heterogeneity in scenario 1. Although the WTD in mountain areas is generally large, it can be much smaller if the aquifer has low permeability (e.g., area indicated by the red circle in Figure 3a). Some previous studies considered either an exponential decay of permeabilities with depth [Jiang et al., 2009] or a vertical anisotropy [Cao et al., 2013]. Scenario 5 with vertical anisotropy has much smaller WTD (Figure S1c).

Scenario 1 with homogeneous permeability in the vertical direction also shows a shift of WTD to $0 \mathrm{~m}$ although it ranges between 0-3 m, indicating that the parameters in Zhang et al. [2018] and/or Gleeson et al. [2014] were likely underestimated. Shallower WTD was also estimated in previous studies [Fan et al., 2013; R. M. Maxwell et al., 2015], which suggested that the bias may be mainly due to GW pumping that was not considered in the simulation. Similarly, GW pumping already happened in the 1970s in the NCP, which might be another reason for the shallower WTD simulated in scenario 1 compared to observations. In general, variations of WTD, decreasing from piedmont plain to coastal plain, are well captured in the simulation. The $\sim 1 \mathrm{~m}$ WTD in the plain areas lies in the sensitive WTD range proposed by Kollet and Maxwell [2008] and Ferguson and Maxwell [2011], in which GW dynamics have larger influence on land surface processes. Following this argument of the sensitive WTD range, long-term GW pumping increasing WTD from $1 \mathrm{~m}$ during predevelopment to more than $10 \mathrm{~m}$ today may have greatly altered the water and energy budgets in the NCP, which is explored in section 3.2. 

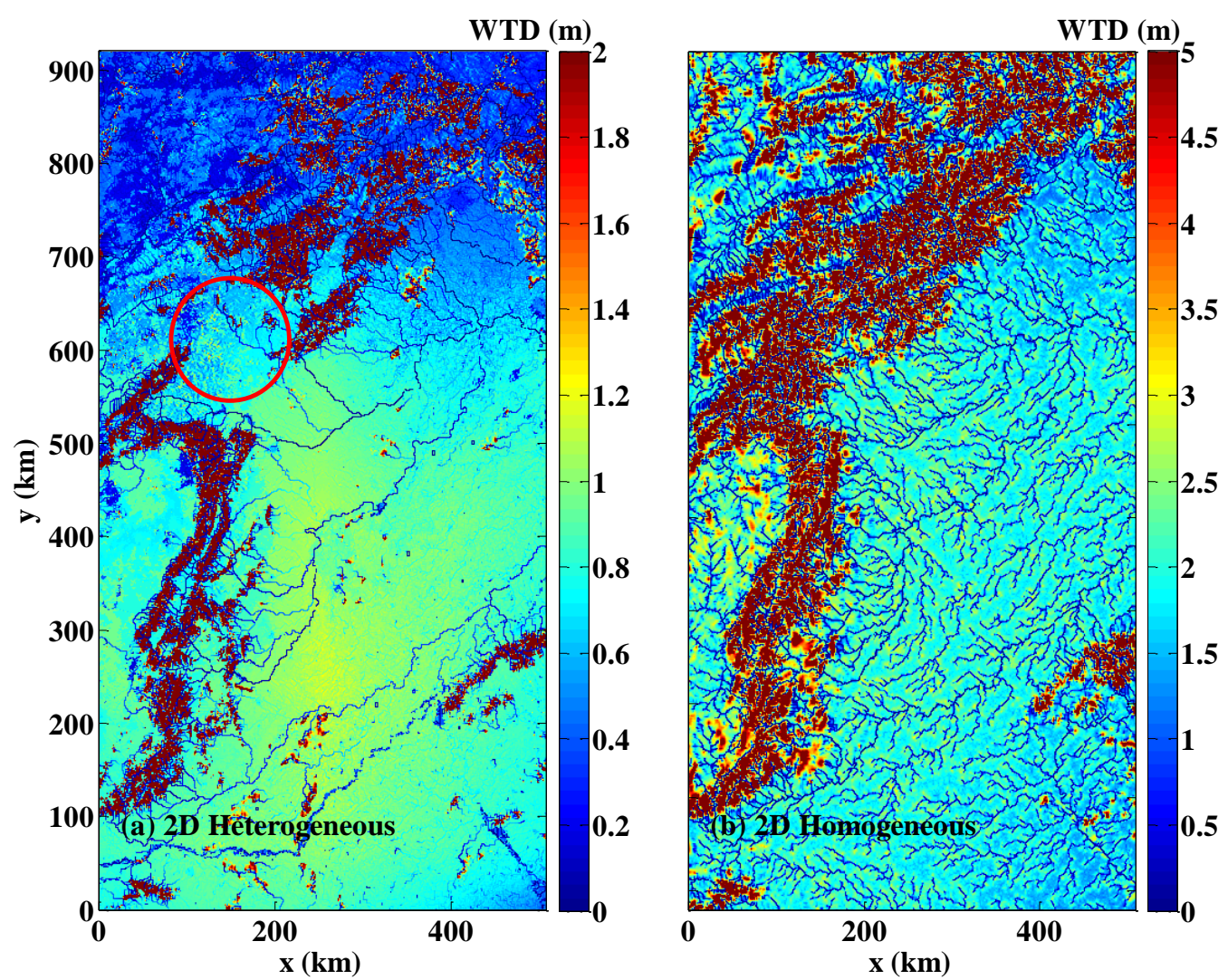

Figure 3. Simulated annual averaged WTD in 1970 for scenarios 1 and 2.

3.1.2. Ground surface temperature and surface heat fluxes

The simulated spatial distribution of annual averaged GST in 1970 (Figure 4a) is consistent with that of the JRA-55 reanalysis data (Figure 5a). GST decreases from about $288 \mathrm{~K}$ in the south to about $278 \mathrm{~K}$ in the northwest. There is a clear difference in GST between the plain and mountain areas due to topography. Seasonal cycle of the simulated GST also matches the trends of JRA-55, showing only a small cold bias (Figure 6a). One possible reason could be the lack of pumping in scenario 1 that is in contrast to the reality in 1970, which will be further studied in section 3.2. The capability to capture the temporal and spatial variations of GST supports the use of the model to study the effects of GW pumping on GST in the NCP.

Spatial distribution of the simulated sensible $(\mathrm{H})$ and latent (LE) heat fluxes are shown in Figure 4. A narrow band with higher $\mathrm{H}$ is simulated between the mountain and plain areas. LE has a more uniform distribution, with slightly higher values in the northeast and south. These spatial patterns are quite consistent with those of JRA-55 shown in Figure 5. The general temporal variability of $\mathrm{H}$ and LE is comparable to that of JRA-55. It is also noted that 1D forcing produces higher GST than 2D forcing (Figure S2a). Correspondingly, lower H and higher LE are obtained 
307 by using 1D relative to 2D forcing (Figure S2). 2D forcing generally produces more realistic results 308 (Figure S2), suggesting the importance to represent the spatial variability of atmospheric forcing 309 in the NCP region. With 1D forcing, energy related variables (GST, H, and LE) exhibit minimal 310 difference under different subsurface heterogeneities (Figure S2). Whereas, the WTD is more 311 controlled by the subsurface heterogeneity than the forcing (Figures 3 and S1).
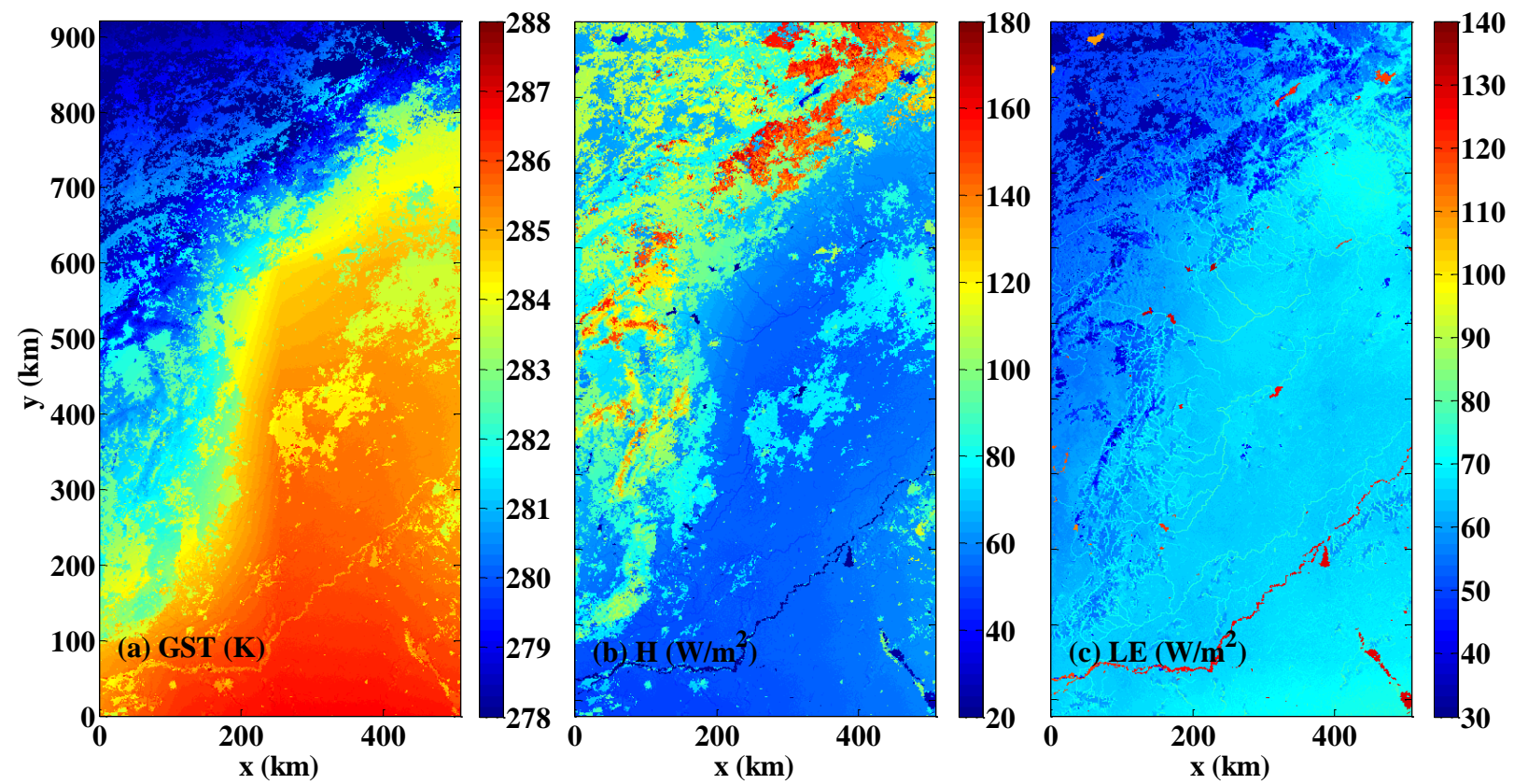

Figure 4. Simulated annual averaged GST, H, and LE in 1970 for scenario 1. 

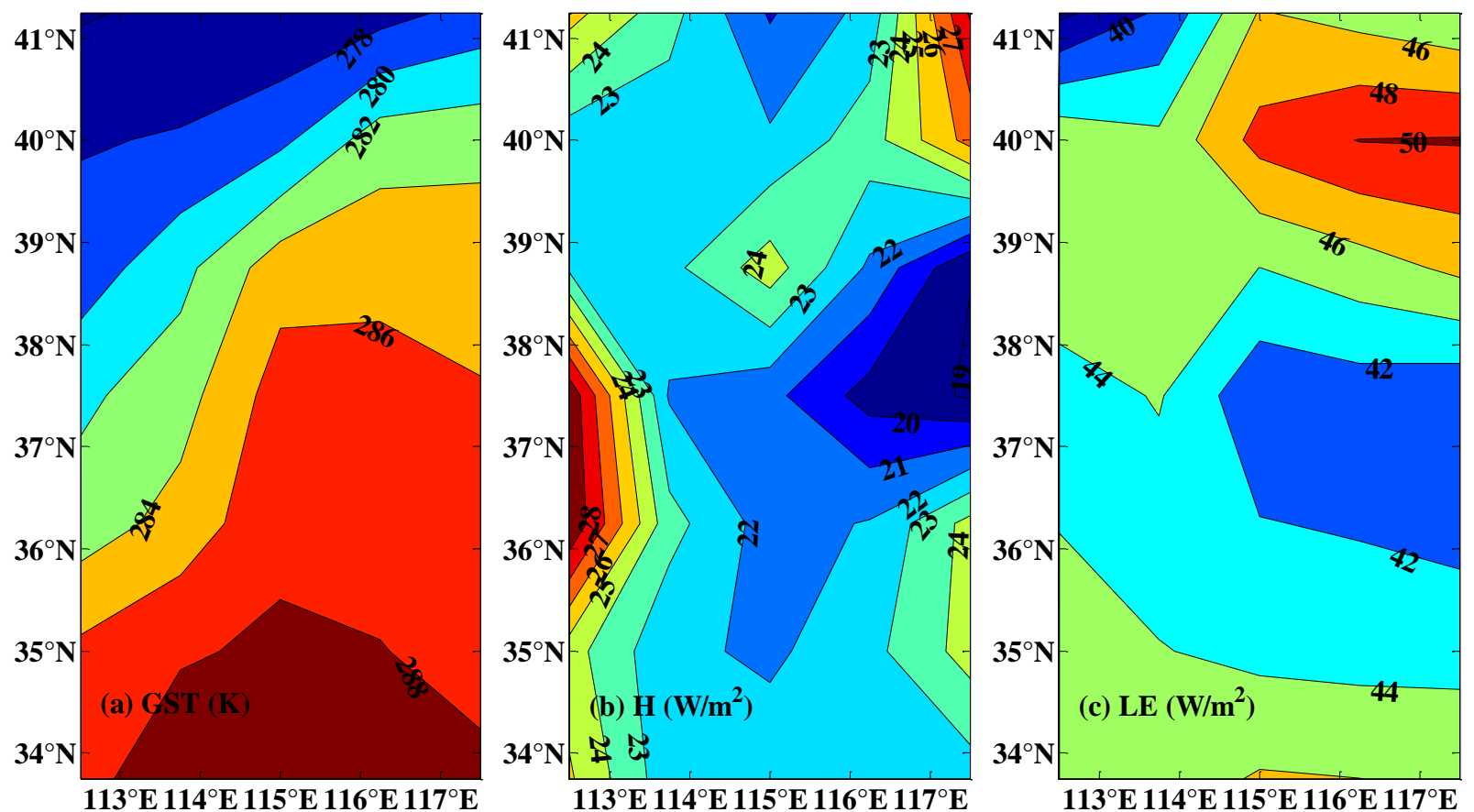

Figure 5. Annual averaged GST, $H$, and LE in 1970 based on the JRA-55 data of 3-hours resolution in time and 1.25-degree resolution in space.
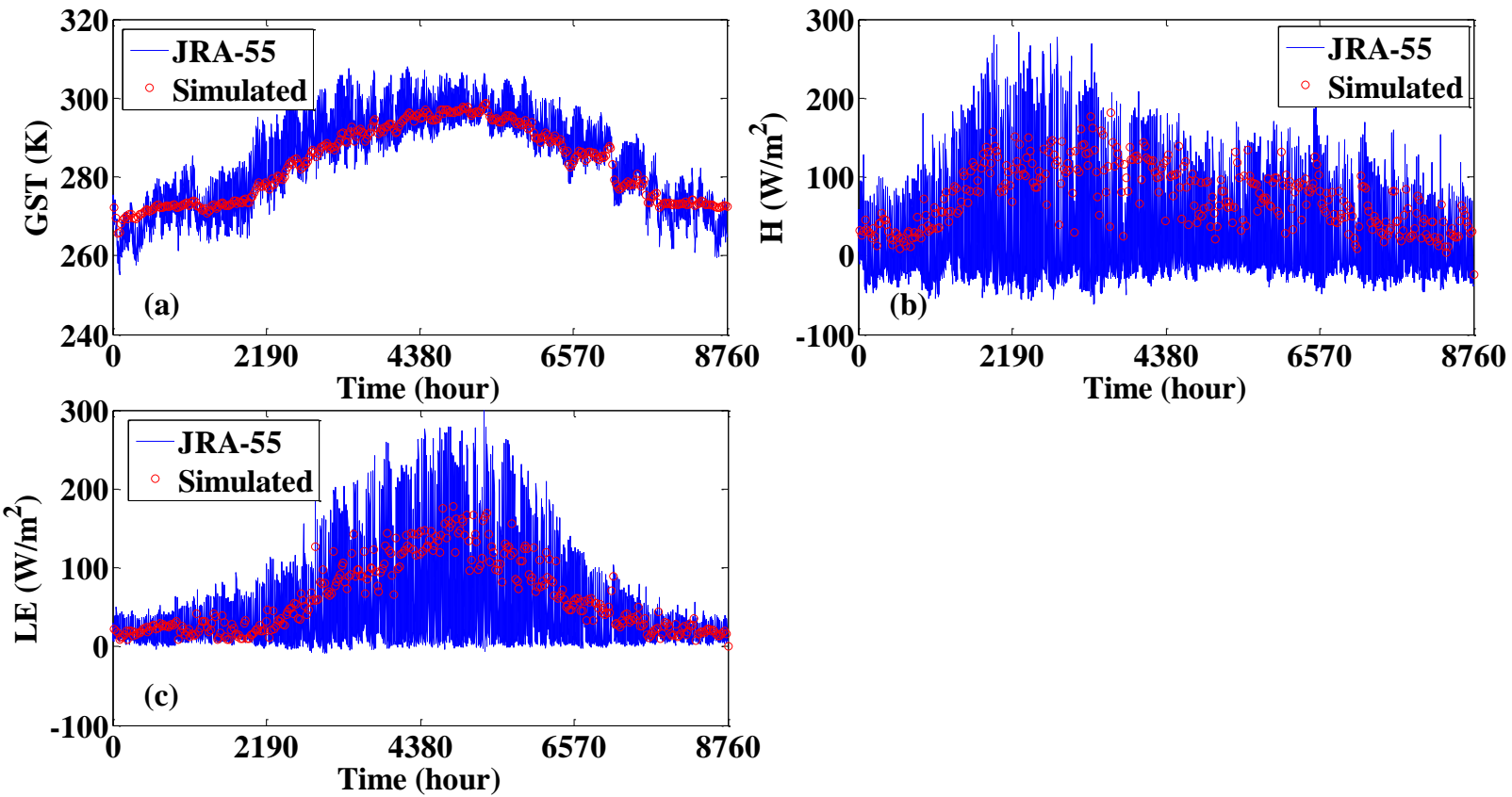

Figure 6. Spatially averaged variations of GST, H, and LE with time in 1970 for scenario 1. 


\subsection{Effects of groundwater pumping and irrigation}

Evaluation of the simulated water and energy components discussed in section 3.1 indicates the feasibility to conduct GW pumping and P\&I using the ParFlow.CLM model. Increase of WTD $(\triangle \mathrm{WTD})$ after one and two years of pumping is shown in Figure 7 . The most obvious increase occurs in Beijing, western Hebei, and Henan, while smaller increase in WTD is found in Tianjin and Shandong due to the smaller pumping rates (Table 2). However, WTD in northern Hebei increases less than other parts of Hebei (red circles in Figure 7), which could be due to the lateral flow recharge from nearby Tianjin and Shandong with less pumping. Besides, the Taihang Mountain next to this area with higher permeability (Figure 2f) might also induce lateral flow from mountain area toward the east. The lateral flow simulated in these areas have been confirmed by field observations (Figure S3) [Li, 2013]. In Figure S3, WTD is larger in Beijing and along the Taihang mountain, then decreases toward Shandong and Tianjin in the east, and is relatively smaller in northern Hebei. These consistencies between the modeling results and observations further demonstrate the fidelity of the model.

WTD in the plain areas increases by less than $0.5 \mathrm{~m}$ after one year of pumping, and by almost $1 \mathrm{~m}$ in some places such as Beijing after 2 years of pumping. The rate of WTD increase $(\sim 0.5$ $\mathrm{m}$ /year) is higher than that reported ( $0.3 \mathrm{~m} / \mathrm{year})$ in Cao et al. [2013] because they calculated an average rate for the whole NCP without considering the spatial variability as shown in Figure 7. In addition, ignoring irrigation might have exaggerated the impacts of pumping on WTD in our simulation. However, considering the uneven spatial distribution of the cone of depression, the rate could also be underestimated by our model. For example, the WTD increase for the cone of depression in Baoding from 1975 to 1985 is more than $1.6 \mathrm{~m}$ per year [ $\mathrm{Li}, 2013]$. With irrigation, WTD increase became slow and the maximum increase of WTD after two years of simulation was about $0.5 \mathrm{~m}$, which is more consistent with Cao et al. [2013]. In general, the spatial and temporal variations of WTD are reasonable in the pumping and irrigation experiments.

Change of monthly averaged GST after one year of pumping is shown in Figure 8, and that after 2 years of pumping is shown in Figure S4. Notably, obvious changes of GST only occurred in the area with pumping. GST in the plain area is less disturbed by pumping from December to February. GST increases from April to July mainly in Beijing and northern Hebei, while it decreases from September to November in Beijing, western Hebei and Henan. Of particular interest is the larger increase of GST in summer than the decrease of GST in winter, leading to an 
357 increasing annual average GST. Taking Beijing for example, the average and maximum increase 358 of GST in summer (May to July) are 0.23 and $1.06{ }^{\circ} \mathrm{C}$ respectively; while the average and maximum decrease of GST in winter (September to Novemeber) are 0.11 and $0.69^{\circ} \mathrm{C}$ respectively. H Zhang et al. [2016] reported an increase in annual mean GST of 2.07-4.04 and $0.66-2.21{ }^{\circ} \mathrm{C}$ in northern and southern China (1962-2011), respectively. The maximum increase of GST per year due to pumping modeled in this study is over $1^{\circ} \mathrm{C}$, suggesting potentially a significant contribution of pumping to the reported GST change. An increase in GST of about $2^{\circ} \mathrm{C}$ for cropland associated with WTD ranging from 2 to $5 \mathrm{~m}$ was reported by Kollet and Maxwell [2008]. In addition, the increase in GST in a one-year simulation was $1-3^{\circ} \mathrm{C}$ as reported by $R$. M. Maxwell and Kollet [2008] under prescribed hot and dry climatic condition in the future. Our results are comparable to the GST changes reported in previous studies.

In addition, by changing the pumping rates in scenario 6 , nonlinear variations of $\Delta \mathrm{GST}$ were obtained. Taking June in Beijing as an example, the average $\Delta$ GST with double pumping rate scenario $\left(0.61^{\circ} \mathrm{C}\right)$ is about twice as large as the $\Delta \mathrm{GST}$ with normal pumping rate $\left(0.33^{\circ} \mathrm{C}\right)$. In comparison, when the pumping rate is reduced to half, the average $\Delta$ GST becomes about one third $\left(0.10^{\circ} \mathrm{C}\right)$ of that under normal rate $\left(0.33^{\circ} \mathrm{C}\right)$. More importantly, one year of pumping with double rate generated higher $\Delta \mathrm{GST}$ than two years of pumping with normal rate, which can be observed in Figure S5, such as the increase of GST in May and the decrease of GST in October. Therefore, moderate pumping rate under sound water management is important for sustainability of water resources and sustainable development of ecological environment. With irrigation, the increase and decrease of GST are obviously alleviated (Figures 9 and S6), but cannot be completely eliminated. Applying pumping and irrigation to crop areas in the Washita watershed, Ferguson and Maxwell [2011] found that pumping led to an increase of WTD over 15\% of the watershed area while irrigation led to a decrease of WTD in only $1.6 \%$ of the watershed, which also indicates the limited compensation of irrigation. As irrigation provides water needed for crop growth, a large

382 fraction of irrigation water supply is balanced by increases in evapotranspiration, so irrigation has 383 smaller effect on WTD than pumping. 

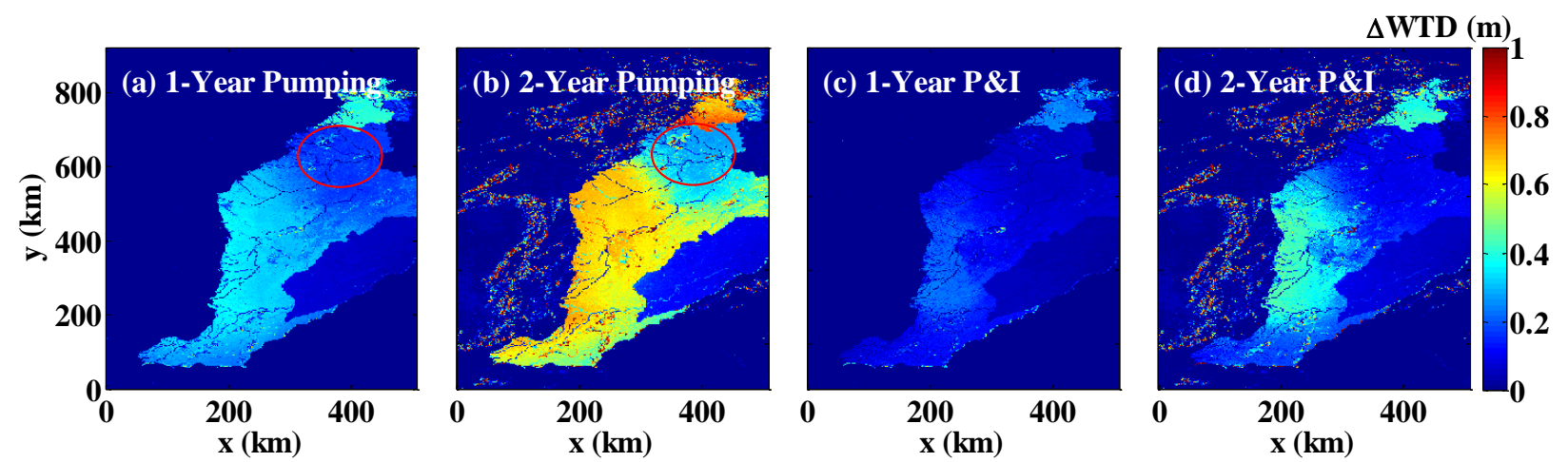

Figure 7. Simulated change of annual averaged WTD after one year of pumping (a), 2 years of pumping (b), one year of pumping and irrigation (c), and 2 years of pumping and irrigation (d).
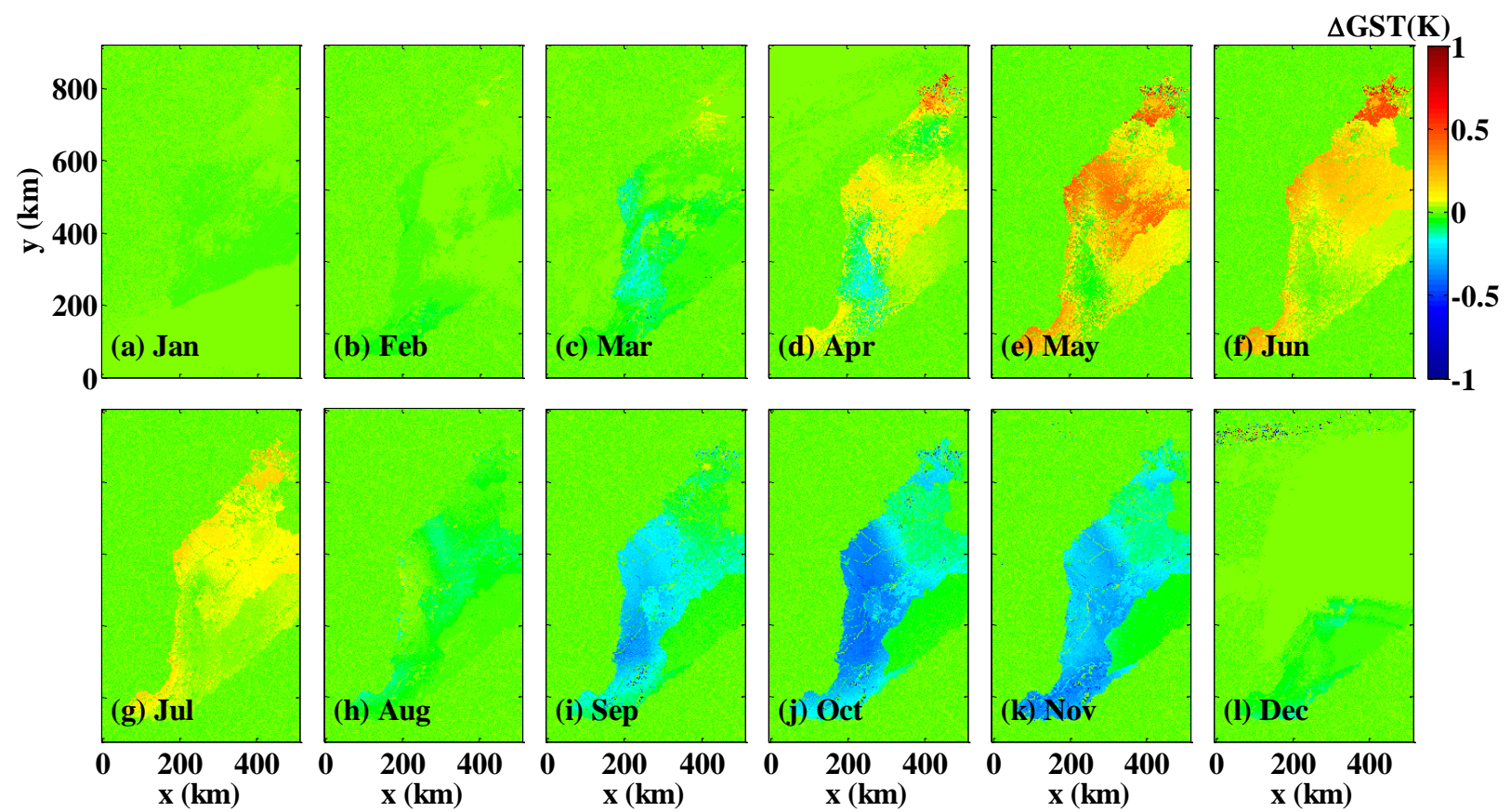

Figure 8. Simulated change of monthly averaged GST after one year of pumping. 

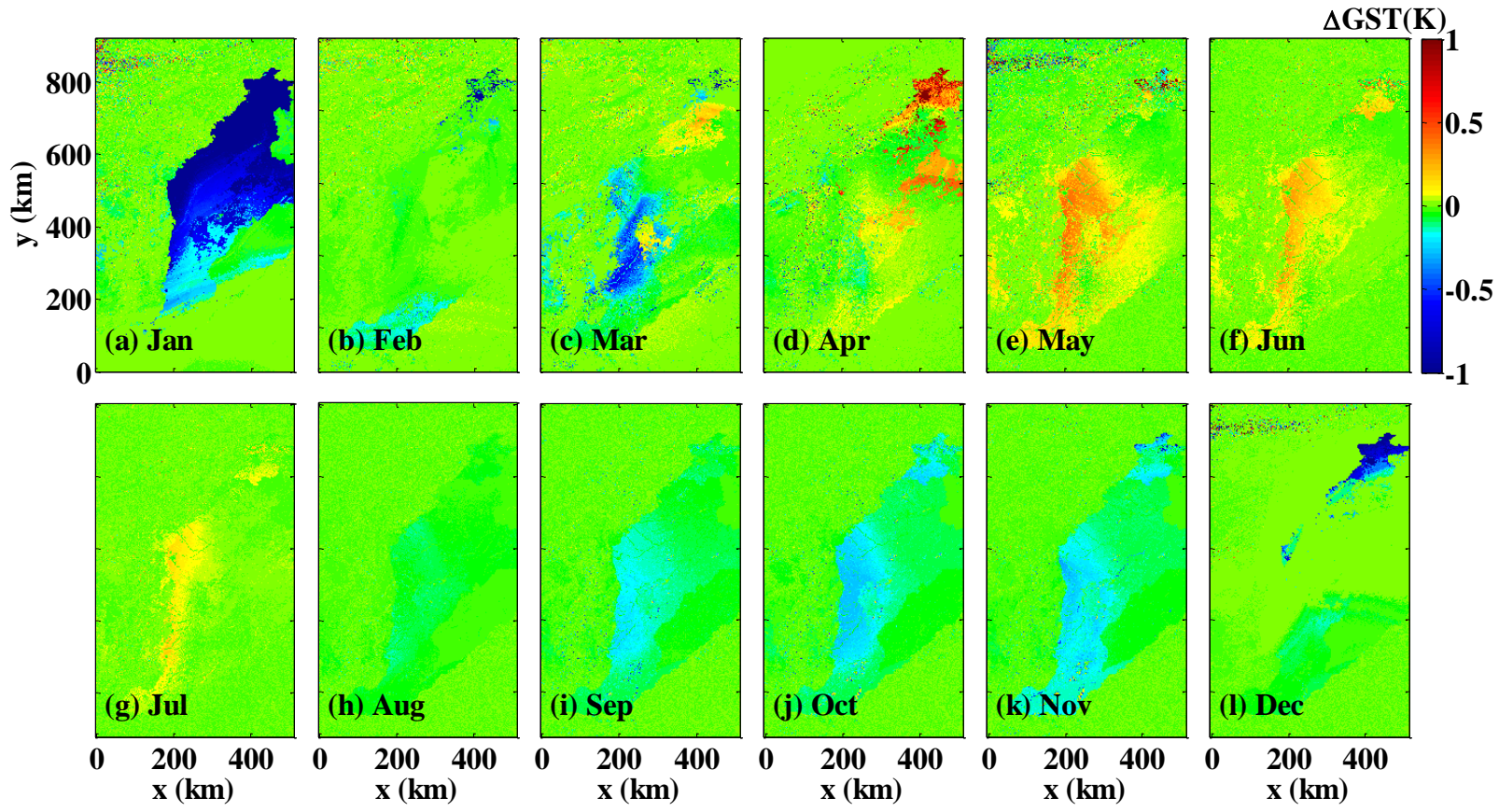

Figure 9. Simulated change of monthly averaged GST after one year of pumping and irrigation.

\subsection{Mechanisms and implications}

Soil heat transport in CLM 3.0 is solved by the heat balance and conduction equations written as (1) and (2), respectively [Dai et al., 2003; Kollet et al., 2009], in the vertical direction:

$$
c \frac{\partial T}{\partial t}=-\frac{\partial F}{\partial z}+S
$$

$$
F=-\lambda \frac{\partial T}{\partial z}
$$

where $c$ is the volumetric heat capacity; $T$ is the soil temperature, which is GST at the land surface; $t$ is time; $F$ is the heat flux and at the land surface, it is the ground heat flux $(\mathrm{G}) ; z$ is the vertical distance from the soil surface and is positive downward; $S$ is the latent heat of phase change; and $\lambda$ is the thermal conductivity. As the top boundary condition in modeling heat transport in the subsurface, G might be a factor inducing variations in GST. The monthly averaged changes of LE,

$\mathrm{H}$, and $\mathrm{G}$ after one year of pumping are shown in Figures S7, S8, and 10, respectively. With increasing WTD by pumping, LE decreases and $\mathrm{H}$ increases, consistent with the general subsurface-land-surface feedback mechanism reflected by the increase of Bowen ratio [Keune et al., 2016; Pal and Eltahir, 2001]. The increase of G in summer from April to July may contribute to the increase of GST at the same time. However, increasing G is also simulated while GST decreases in autumn and winter from September to November. Considering that soil moisture 
411 decreases with pumping, the volumetric heat capacity decreases [Abu-Hamdeh, 2003] so the heat

412 storage/release capacity of the subsurface decreases. Therefore, in summer, heat flux into the 413 subsurface combined with reduced heat storage capacity increase GST. In winter, reduced heat 414 flux released from the subsurface due to the reduced heat storage in summer leads to the decrease 415 in GST even though G increases.
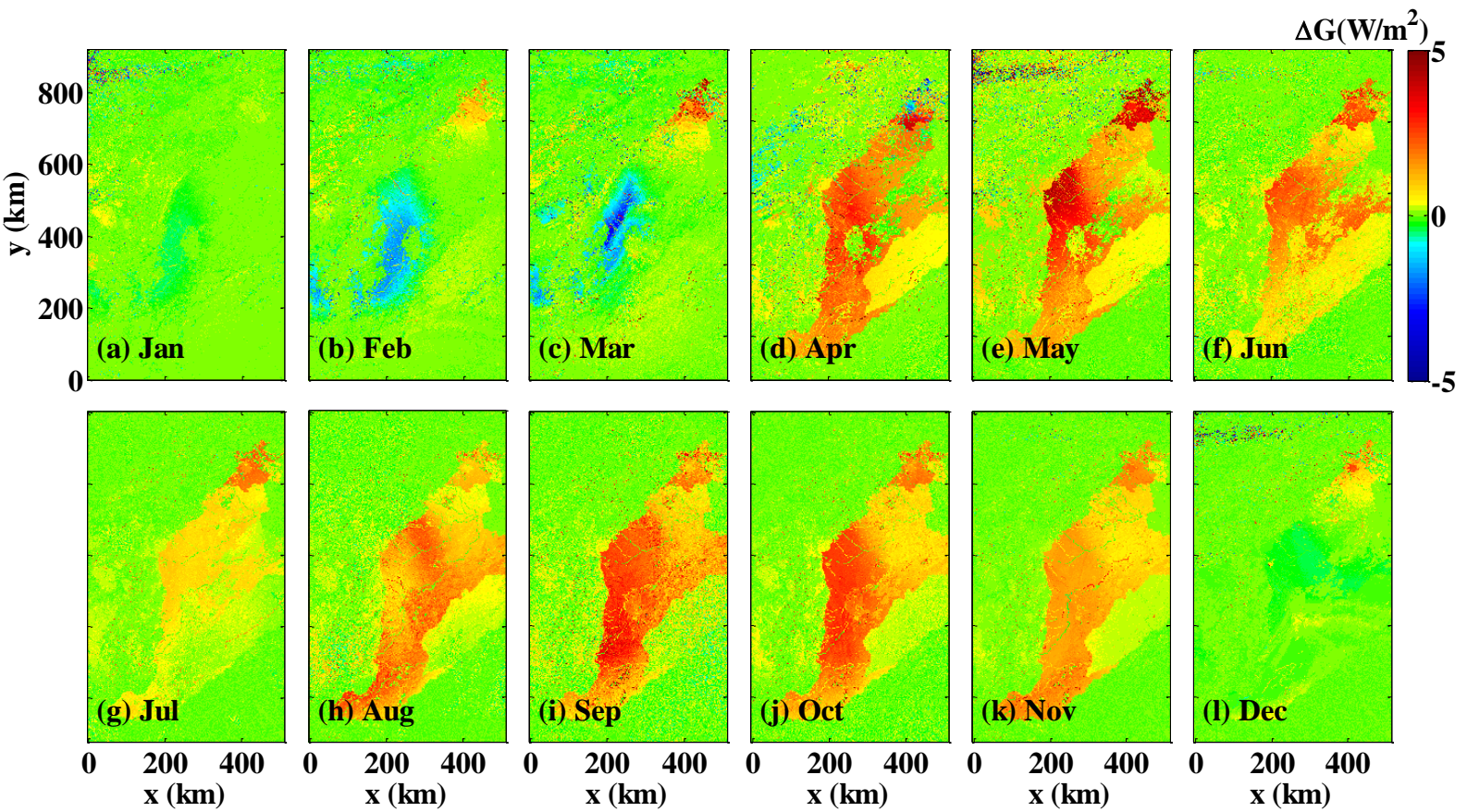

Figure 10. Simulated change of monthly averaged $G$ after one year of pumping.

Previous studies suggested that WTD may have larger influence on land surface heat fluxes when it is within a specific range of depths [e.g., Maxwell and Kollet, 2008]. Often GW supplies moisture for surface heat fluxes when WTD is shallow. In contrary, when the water table is too deep, GW has little influence on soil moisture that contributes to surface heat fluxes. The thresholds of such range was well-stated by numerous previous case studies [Ferguson and Maxwell, 2010; Kollet and Maxwell, 2008; Reed M. Maxwell et al., 2007; Szilagyi et al., 2013] and summarized as 1-10 m [Ferguson and Maxwell, 2011]. In Condon et al. [2013], possible influencing factors on the critical depth range were sysmeitcally studied. Results revealed that the critical range does not vary significantly with subsurface parameters. Though land cover and soil types affect the shape of the relationship between WTD and land surface heat fluxes, the bulk range of the critical depth stays the same. Hence, the 1-10 m critical depth range in [Ferguson and 
Maxwell, 2011] was aopted for the following discussion. Therefore, with the $0.5 \mathrm{~m}$ increase of WTD per year estimated due to pumping, WTD may continue to increase from the 1970, i.e., prepumping condition, for about 20 years until the average WTD drops below $10 \mathrm{~m}$. Hence pumping could have influenced GST for one decade or two. Considering the uneven WTD-distribution of a depression-cone, the pumping influence can last longer time than 20 years regionally. Considering the nonlinear change of GST with WTD discussed in section 3.2, the increase of GST should be faster in the beginning and gradually slow down. Generally, the subsurface acts as a buffer to heat fluxes at the land surface but long-term pumping can gradually weaken and finally invalidate this buffer when the water table becomes too deep. The weakened buffer can result in higher temporal variability of GST, i.e., colder winter and hotter summer. Although irrigation alleviates the impacts of pumping by increasingsoil moisture at the land surface, it cannot completely eliminate the pumping effect.

\subsection{Limitations and future work}

Our modeling and analyses could be potentially improved in a few directions, although we do not expect them to have large influence on our major conclusions. More information on the temporal and spatial variations of pumping and irrigation in the NCP during the past 60 years may be used to further constrain the model setup in future studies. The NCP is also influenced by urbanization, which deserves attention when attributing changes in GST in the region. For example, land use data of the NCP in 2003 [Cao et al., 2014] and 2009 [Pei et al., 2015] illustrates that urban regions scattered among croplands have expanded gradually. Urban expansion can alter the spatial distribution of irrigation regions by reducing their sizes and fragmenting their coverage. Meanwhile, a depression cone can continue to expand from its center located mainly in the irrigation regions to a much broader area. Urban areas located outside the irrigation regions may sit on top of some cones of depression far away. Near the edges of the groundwater cones of depression, the shallow WTD may stay within the critical zone (WTD of 1-10 m), so the effect of pumping can be significant when irrigation is not regulated. In this study, sprinkler irrigation is applied by adding the irrigation water to precipitation. However, flood irrigation is the most popular irrigation method in the NCP [Cao et al., 2013]. Flood irrigation has lower water utilization efficiency [Kendy et al., 2007; Scanlon et al., 2012] than sprinkler irrigation, which can lead to larger increase in GST than what we obtained in this study. Flood irrigation has not been implemented in ParFlow.CLM so that future work should consider modeling different irrigation 
methods to allow investigation into their specific impacts [Delos Reyes and Schultz, 2019; Leng et al., 2017].

Future work could also improve modeling of land surface processes as heat transport in CLM is described using a one-dimensional vertical model, while in the ParFlow groundwater flow is modeled using the three-dimensional Richards' equation. This approach is reasonable for modeling energy and water fluxes in regions in an energy limited regime and human influence is small. However, with human activities such as GW pumping, horizontal temperature gradient may be induced, so horizontal heat transport should not be neglected. Other shortcomings of the modeling approach include the limited soil depth and the simple lower boundary condition implemented in CLM for heat transport. Davison et al. [2015] investigated the sensitivity of GST simulations to soil depth using aquifers of $2 \mathrm{~m}$ and $8 \mathrm{~m}$ depth in 100 days of simulation under prolonged drought condition. Although GST shows no difference between the two settings, deep soil temperature $(>1 \mathrm{~m})$ is higher for the simulation with aquifer depth of $2 \mathrm{~m}$. With longer simulations, the difference of deep soil temperature becomes greater and propagates to the land surface so GST may be expected to be different in the two settings after 100 days of simulation. Since GW pumping has been practiced in the NCP for more than 60 years, future studies should also consider increasing the model soil depth for heat transport. The critical depth of WTD proposed by Kollet and Maxwell [2008] was based on a one-year simulation, showing that the deficiency related to heat transport at depth can be neglected.

\section{Conclusions}

In this study, integrated land surface-subsurface modeling of the NCP was performed using ParFlow.CLM. The model produced realistic water and energy dynamics that are highly consistent with those in previous studies and from the JRA-55 data, respectively. Both the spatial and temporal variations of water and energy processes were well captured by the integrated model. Based on a suite of numerical experiments, the effects of GW pumping and combined pumping and irrigation on water and energy were explored, with a focus on the ground surface temperature (GST) which was rarely discussed in previous studies. Results show significant effects of GW pumping on the GST in the NCP. Generally, the subsurface acts as a buffer to heat fluxes at the land surface, but long-term pumping can gradually weaken and finally invalidate this buffer. This 
results in higher temporal variability of GST, featuring hotter summer and colder winter. Increased spatial variabilities of GST was also captured.

Considering that changes of WTD can significantly affect surface heat fluxes for WTD roughly in the range of $1-10 \mathrm{~m}$, the $0.5 \mathrm{~m} / \mathrm{year}$ increase of WTD can continuously increase GST for at least 20 years based on the 1970 average WTD in the NCP. If the uneven WTD distribution of depression cones is also considered, this influence could last until the WTD in the whole NCP increases by over $10 \mathrm{~m}$, which may take longer than 20 years. In addition, GST is expected to increase faster at the beginning and gradually slow down due to the nolinear variations of GST with WTD. Irrigation alleviates this situation by increasing soil moisture at the land surface but it cannot completely eliminate the pumping effect. Considering the spatial and temporal variations of pumping and irrigation, urbanization, and how irrigation was modeled in this study, the effect of irrigation might be overestimated.

This study aimed to build a realistic modeling platform to understand the water and energy cycles and their interactions in a subsurface-land-surface system. Hence no efforts were devoted to establishing a calibrated model to fit the historical data or to predict future changes. Unlike previous studies that modeled the surface and subsurface as separated systems in the NCP, the coupled ParFlow.CLM model provides an important tool for more investigations of pumping and irrigation in the context of climate change in the future. GW pumping has already been a global problem and occurs not only in the NCP but also in northwestern India, Middle East, the U.S. High Plains [Famiglietti, 2014] and other regions. Hence the results of this study may have implications for other regions with GW depletion and motivate the need to investigate the role of GW pumping in regional climate change.

\section{Acknowledgement}

This study was supported by the Strategic Priority Research Program of Chinese Academy of Sciences (Grant No. XDA20100104) and the National Natural Science Foundation of China (Grant No. 41807198) and the Center for Computational Science and Engineering of Southern University of Science and Technology. HL, YF and LRL were supported by the U.S. Department of Energy Office of Science Biological and Environmental Research as part of the Earth System Modeling program. PNNL is operated for the Department of Energy under contract DE-AC05-76RL01830. 


\section{References}

A, D., K. Xiong, W. J. Zhao, Z. N. Gong, R. Jing, and L. Zhang (2016), Temporal Trend of Climate Change and Mutation Analysis of North China Plain During 1960 to 2013 [in Chinese with English abstract], Scientia Geographica Sinica, 36(10), 1555-1564.

Abu-Hamdeh, N. H. (2003), Thermal properties of soils as affected by density and water content, Biosyst Eng, 86(1), 97-102, doi:10.1016/S1537-5110(03)00112-0.

Alkhaier, F., G. N. Flerchinger, and Z. Su (2012), Shallow groundwater effect on land surface temperature and surface energy balance under bare soil conditions: modeling and description, Hydrol Earth Syst Sc, 16(7), 1817-1831, doi:10.5194/hess-16-1817-2012.

Ashby, S. F., and R. D. Falgout (1996), A parallel multigrid preconditioned conjugate gradient algorithm for groundwater flow simulations, Nucl Sci Eng, 124(1), 145-159.

Bisht, G., W. J. Riley, H. M. Wainwright, B. Dafflon, F. M. Yuan, and V. E. Romanovsky (2018), Impacts of microtopographic snow redistribution and lateral subsurface processes on hydrologic and thermal states in an Arctic polygonal ground ecosystem: a case study using ELM-3D v1.0, Geosci Model Dev, 11(1), 61-76, doi:10.5194/gmd-11-61-2018.

Cao, G. L., D. M. Han, and X. F. Song (2014), Evaluating actual evapotranspiration and impacts of groundwater storage change in the North China Plain, Hydrol Process, 28(4), 1797-1808, doi:10.1002/hyp.9732.

Cao, G. L., C. M. Zheng, B. R. Scanlon, J. Liu, and W. P. Li (2013), Use of flow modeling to assess sustainability of groundwater resources in the North China Plain, Water Resour Res, 49(1), 159-175, doi:10.1029/2012wr011899.

Condon, L. E., and R. M. Maxwell (2014a), Feedbacks between managed irrigation and water availability: Diagnosing temporal and spatial patterns using an integrated hydrologic model, Water Resour Res, 50(3), 2600-2616, doi:10.1002/2013wr014868.

Condon, L. E., and R. M. Maxwell (2014b), Groundwater-fed irrigation impacts spatially distributed temporal scaling behavior of the natural system: a spatio-temporal framework for understanding water management impacts, Environ Res Lett, 9(3), doi:Artn 03400910.1088/1748-9326/9/3/034009.

Condon, L. E., and R. M. Maxwell (2019), Simulating the sensitivity of evapotranspiration and streamflow to large-scale groundwater depletion, Sci Adv, 5(6), doi:ARTN eaav457410.1126/sciadv.aav4574.

Condon, L. E., R. M. Maxwell, and S. Gangopadhyay (2013), The impact of subsurface conceptualization on land energy fluxes, Adv Water Resour, 60, 188-203, doi:10.1016/j.advwatres.2013.08.001.

Cui, Y., Y. Wang, J. Shao, Y. Chi, and L. Lin (2009), Research on groundwater regulation and recovery in North China Plain after the implementation of south-to-north water transfer [in Chinese with English abstract], Resour. Sci., 31(3), 382-387.

Dai, Y. J., et al. (2003), The Common Land Model, B Am Meteorol Soc, 84(8), 1013-1023, doi:10.1175/Bams-84-8-1013.

Davidson, E. A., I. A. Janssens, and Y. Q. Luo (2006), On the variability of respiration in terrestrial ecosystems: moving beyond Q(10), Global Change Biol, 12(2), 154-164, doi:10.1111/j.13652486.2005.01065.x.

Davison, J. H., H. T. Hwang, E. A. Sudicky, and J. C. Lin (2015), Coupled atmospheric, land surface, and subsurface modeling: Exploring water and energy feedbacks in three-dimensions, Adv Water Resour, 86, 73-85, doi:10.1016/j.advwatres.2015.09.002.

Delos Reyes, M. L. F., and B. Schultz (2019), Modernization of National Irrigation Systems in the Philippines: Linking Design, Operation and Water Supply, Irrigation and Drainage, 68(1), 59-66, doi:10.1002/ird.2260.

Famiglietti, J. S. (2014), The global groundwater crisis, Nat Clim Change, 4(11), 945-948.

Fan, Y., H. Li, and G. Miguez-Macho (2013), Global Patterns of Groundwater Table Depth, Science, 339(6122), 940-943, doi:10.1126/science.1229881.

Fang, Y. L., L. R. Leung, Z. R. Duan, M. S. Wigmosta, R. M. Maxwell, J. Q. Chambers, and J. Tomasella (2017), Influence of landscape heterogeneity on water available to tropical forests in an Amazonian 
604

605

606

607

608

609

610

611

612

613

614

615

616

617

618

619

620

621

622

catchment and implications for modeling drought response, J Geophys Res-Atmos, 122(16), 84108426, doi:10.1002/2017jd027066.

Fei, Y. H., J. X. Miao, Z. J. Zhang, Z. Y. Chen, H. B. Song, and M. Yang (2009), Analysis on Evolution of Groundwater Depression Cones and Its Leading Factors in North China Plain [in Chinese with English abstract], Resources Science, 31(3), 394-399.

Ferguson, I. M., J. L. Jefferson, R. M. Maxwell, and S. J. Kollet (2016), Effects of root water uptake formulation on simulated water and energy budgets at local and basin scales, Environ Earth Sci, 75(4), doi:ARTN 31610.1007/s12665-015-5041-z.

Ferguson, I. M., and R. M. Maxwell (2010), Role of groundwater in watershed response and land surface feedbacks under climate change, Water Resour Res, 46.

Ferguson, I. M., and R. M. Maxwell (2011), Hydrologic and land-energy feedbacks of agricultural water management practices, Environ Res Lett, 6(1), doi:Artn 01400610.1088/1748-9326/6/1/014006.

Ferguson, I. M., and R. M. Maxwell (2012), Human impacts on terrestrial hydrology: climate change versus pumping and irrigation, Environ Res Lett, 7(4), doi:Artn 04402210.1088/1748-9326/7/4/044022.

Gao, Y. (2008), Study on Groundwater Hydraulic Connection in Different Aquifers under mass Pumped Conditions in Typical Area North China Plain, 147 pp, Chinese Academy of Geological Sciences, Beijing.

Gleeson, T., N. Moosdorf, J. Hartmann, and L. P. H. van Beek (2014), A glimpse beneath earth's surface: GLobal HYdrogeology MaPS (GLHYMPS) of permeability and porosity, Geophys Res Lett, 41(11), 3891-3898, doi:10.1002/2014g1059856.

Gleeson, T., L. Smith, N. Moosdorf, J. Hartmann, H. H. Durr, A. H. Manning, L. P. H. van Beek, and A. M. Jellinek (2011), Mapping permeability over the surface of the Earth, Geophys Res Lett, 38, doi:Artn L0240110.1029/2010g1045565.

Harada, Y., H. Kamahori, C. Kobayashi, H. Endo, S. Kobayashi, Y. Ota, H. Onoda, K. Onogi, K. Miyaoka, and K. Takahashi (2016), The JRA-55 Reanalysis: Representation of Atmospheric Circulation and Climate Variability, J Meteorol Soc Jpn, 94(3), 269-302, doi:10.2151/jmsj.2016-015.

Hu, Y. K., J. P. Moiwo, Y. H. Yang, S. M. Han, and Y. M. Yang (2010), Agricultural water-saving and sustainable groundwater management in Shijiazhuang Irrigation District, North China Plain, J. Hydrol., 393(3-4), 219-232.

Jefferson, J. L., and R. M. Maxwell (2015), Evaluation of simple to complex parameterizations of bare ground evaporation, $J$ Adv Model Earth Sy, 7(3), 1075-1092, doi:10.1002/2014ms000398.

Jefferson, J. L., R. M. Maxwell, and P. G. Constantine (2017), Exploring the Sensitivity of Photosynthesis and Stomatal Resistance Parameters in a Land Surface Model, J Hydrometeorol, 18(3), 897-915, doi:10.1175/Jhm-D-16-0053.1.

Jia, J., and C. Liu (2002), Groundwater dynamic drift and response to different exploitation in the North China Plain: A case study of Luancheng County, Hebei Province [in Chinese with English abstract], Acta Geogr. Sin., 57(2), 201-209.

Jiang, X. W., L. Wan, X. S. Wang, S. M. Ge, and J. Liu (2009), Effect of exponential decay in hydraulic conductivity with depth on regional groundwater flow, Geophys Res Lett, 36, doi:Artn L2440210.1029/2009g1041251.

Jones, J. E., and C. S. Woodward (2001), Newton-Krylov-multigrid solvers for large-scale, highly heterogeneous, variably saturated flow problems, Adv Water Resour, 24(7), 763-774.

Kang, S., and E. A. B. Eltahir (2018), North China Plain threatened by deadly heatwaves due to climate change and irrigation, Nat Commun, 9, doi:ARTN 289410.1038/s41467-018-05252-y.

Kendy, E., J. X. Wang, D. J. Molden, C. Zheng, C. M. Liu, and T. S. Steenhuis (2007), Can urbanization solve inter-sector water conflicts? Insight from a case study in Hebei Province, North China Plain, Water Policy, 9, 75-93, doi:10.2166/wp.2007.046.

Keune, J., F. Gasper, K. Goergen, A. Hense, P. Shrestha, M. Sulis, and S. Kollet (2016), Studying the influence of groundwater representations on land surface-atmosphere feedbacks during the European heat wave in 2003, J Geophys Res-Atmos, 121(22), 13301-13325, doi:10.1002/2016jd025426.

Kobayashi, S., et al. (2015), The JRA-55 Reanalysis: General Specifications and Basic Characteristics, $J$ 
656

657

658

659

660

661

662

663

664

665

666

667

668

669

670

671

672

673

Meteorol Soc Jpn, 93(1), 5-48, doi:10.2151/jmsj.2015-001.

Kollet, S. J., I. Cvijanovic, D. Schuttemeyer, R. M. Maxwell, A. F. Moene, and P. Bayer (2009), The Influence of Rain Sensible Heat and Subsurface Energy Transport on the Energy Balance at the Land Surface, Vadose Zone J, 8(4), 846-857, doi:10.2136/vzj2009.0005.

Kollet, S. J., and R. M. Maxwell (2006), Integrated surface-groundwater flow modeling: A free-surface overland flow boundary condition in a parallel groundwater flow model, Adv Water Resour, 29(7), 945-958.

Kollet, S. J., and R. M. Maxwell (2008), Capturing the influence of groundwater dynamics on land surface processes using an integrated, distributed watershed model, Water Resour Res, 44(2), doi:Artn W0240210.1029/2007wr006004.

Leng, G., L. R. Leung, and M. Huang (2017), Significant impacts of irrigation water sources and methods on modeling irrigation effects in the ACME Land Model, J Adv Model Earth Sy, 9(3), 1665-1683, doi:10.1002/2016MS000885.

Li, L. (2013), Development of a Numerical Model of Regional Groundwater Flow and its Application to the North China Plain, 97 pp, China University of Geosciences (Beijing), Beijing.

Liu, C. M., J. J. Yu, and E. Kendy (2001), Groundwater exploitation and its impact on the environment in the North China Plain, Water Int, 26(2), 265-272.

Liu, J., C. Zheng, L. Zheng, and Y. Lei (2008), Ground water sustainability: Methodology and application to the North China Plain, Ground Water, 46(6), 897-909.

Lloyd, J., and J. A. Taylor (1994), On the Temperature-Dependence of Soil Respiration, Funct Ecol, 8(3), 315-323, doi:Doi 10.2307/2389824.

Maxwell, R. M., F. K. Chow, and S. J. Kollet (2007), The groundwater-land-surface-atmosphere connection: Soil moisture effects on the atmospheric boundary layer in fully-coupled simulations, $A d v$ Water Resour, 30(12), 2447-2466, doi:https://doi.org/10.1016/j.advwatres.2007.05.018.

Maxwell, R. M., and L. E. Condon (2016), Connections between groundwater flow and transpiration partitioning, Science, 353(6297), 377-380.

Maxwell, R. M., L. E. Condon, and S. J. Kollet (2015), A high-resolution simulation of groundwater and surface water over most of the continental US with the integrated hydrologic model ParFlow v3, Geosci Model Dev, 8(3), 923-937, doi:10.5194/gmd-8-923-2015.

Maxwell, R. M., L. E. Condon, S. J. Kollet, K. Maher, R. Haggerty, and M. M. Forrester (2016), The imprint of climate and geology on the residence times of groundwater, Geophys Res Lett, 43(2), 701-708, doi:10.1002/2015g1066916.

Maxwell, R. M., and S. J. Kollet (2008), Interdependence of groundwater dynamics and land-energy feedbacks under climate change, Nat Geosci, 1(10), 665-669, doi:10.1038/ngeo315.

Maxwell, R. M., J. K. Lundquist, J. D. Mirocha, S. G. Smith, C. S. Woodward, and A. F. B. Tompson (2011), Development of a Coupled Groundwater-Atmosphere Model, Mon Weather Rev, 139(1), 96-116, doi:10.1175/2010mwr3392.1.

Maxwell, R. M., and N. L. Miller (2005), Development of a coupled land surface and groundwater model, J Hydrometeorol, 6(3), 233-247.

Pal, J. S., and E. A. B. Eltahir (2001), Pathways relating soil moisture conditions to future summer rainfall within a model of the land-atmosphere system, J Climate, 14(6), 1227-1242, doi:Doi 10.1175/15200442(2001)014<1227:Prsmct >2.0.Co;2.

Pei, H. W., B. R. Scanlon, Y. J. Shen, R. C. Reedy, D. Long, and C. M. Liu (2015), Impacts of varying agricultural intensification on crop yield and groundwater resources: comparison of the North China Plain and US High Plains, Environ Res Lett, 10(4), doi:Artn 04401310.1088/1748-9326/10/4/044013.

Pollack, H. N., J. E. Smerdon, and P. E. van Keken (2005), Variable seasonal coupling between air and ground temperatures: A simple representation in terms of subsurface thermal diffusivity, Geophys Res Lett, 32(15).

Qin, H., G. Cao, M. Kristensen, J. C. Refsgaard, M. O. Rasmussen, X. He, J. Liu, Y. Shu, and C. Zheng (2013), Integrated hydrological modeling of the North China Plain and implications for sustainable water management, Hydrol Earth Syst Sc, 17(10), 3759-3778. 
Rabus, B., M. Eineder, A. Roth, and R. Bamler (2003), The shuttle radar topography mission - a new class of digital elevation models acquired by spaceborne radar, Isprs $J$ Photogramm, 57(4), 241-262, doi:10.1016/S0924-2716(02)00124-7.

Rahman, M., M. Sulis, and S. J. Kollet (2015), The subsurface-land surface-atmosphere connection under convective conditions, Adv Water Resour, 83, 240-249, doi:10.1016/j.advwatres.2015.06.003.

Scanlon, B. R., C. C. Faunt, L. Longuevergne, R. C. Reedy, W. M. Alley, V. L. McGuire, and P. B. McMahon (2012), Groundwater depletion and sustainability of irrigation in the US High Plains and Central Valley, P Natl Acad Sci USA, 109(24), 9320-9325, doi:10.1073/pnas.1200311109.

Szilagyi, J., V. A. Zlotnik, and J. Jozsa (2013), Net Recharge vs. Depth to Groundwater Relationship in the Platte River Valley of Nebraska, United States, Groundwater, 51(6), 945-951, doi:10.1111/gwat.12007.

Taylor, R. G., et al. (2013), Ground water and climate change, Nat Clim Change, 3(4), 322-329, doi:10.1038/Nclimate1744.

Wang, S., J. Shao, X. Song, Y. Zhang, Z. Huo, and X. Zhou (2008), Application of MODFLOW and geographic information system to groundwater flow simulation in North China Plain, China, Environ. Geol., 55(7), 1449-1462.

Xue, L., W. Li, W. Yang, J. Li, and X. Zhu (2010), Numerical modelling on exploited shallow groundwater flow in the plain of Haihe river basin [in Chinese with English abstract], Geotech. Invest. Survey., 3, 50-55.

Zeng, Y. J., Z. H. Xie, S. Liu, J. B. Xie, B. H. Jia, P. H. Qin, and J. Q. Gao (2018), Global Land Surface Modeling Including Lateral Groundwater Flow, J Adv Model Earth Sy, 10(8), 1882-1900, doi:10.1029/2018ms001304.

Zhang, H., E. L. Wang, D. W. Zhou, Z. K. Luo, and Z. X. Zhang (2016), Rising soil temperature in China and its potential ecological impact, Sci Rep-Uk, 6, doi:ARTN 3553010.1038/srep35530.

Zhang, T., R. G. Barry, D. Gilichinsky, S. S. Bykhovets, V. A. Sorokovikov, and J. P. Ye (2001), An amplified signal of climatic change in soil temperatures during the last century at Irkutsk, Russia, Climatic Change, 49(1-2), 41-76, doi:Doi 10.1023/A:1010790203146.

Zhang, X. (2007), Numerical simulation of the shallow groundwater in the Haihe Basin [in Chinese], Haihe Water Resour., 3, 52-54.

Zhang, X., L. Xue, Q. Zhang, and J. Li (2008), Simulation of groundwater exploitation at early stage and analysis on water budget in Haihe River Basin [in Chinese], J. Arid Land Resour. Environ, 9, 102-107.

Zhang, Y. G., M. G. Schaap, and Y. Y. Zha (2018), A High-Resolution Global Map of Soil Hydraulic Properties Produced by a Hierarchical Parameterization of a Physically Based Water Retention Model, Water Resour Res, 54(12), 9774-9790, doi:10.1029/2018wr023539.

Zou, J., Z. H. Xie, C. S. Zhan, P. H. Qin, Q. Sun, B. H. Jia, and J. Xia (2015), Effects of anthropogenic groundwater exploitation on land surface processes: A case study of the Haihe River Basin, northern China, J Hydrol, 524, 625-641, doi:10.1016/j.jhydrol.2015.03.026. 

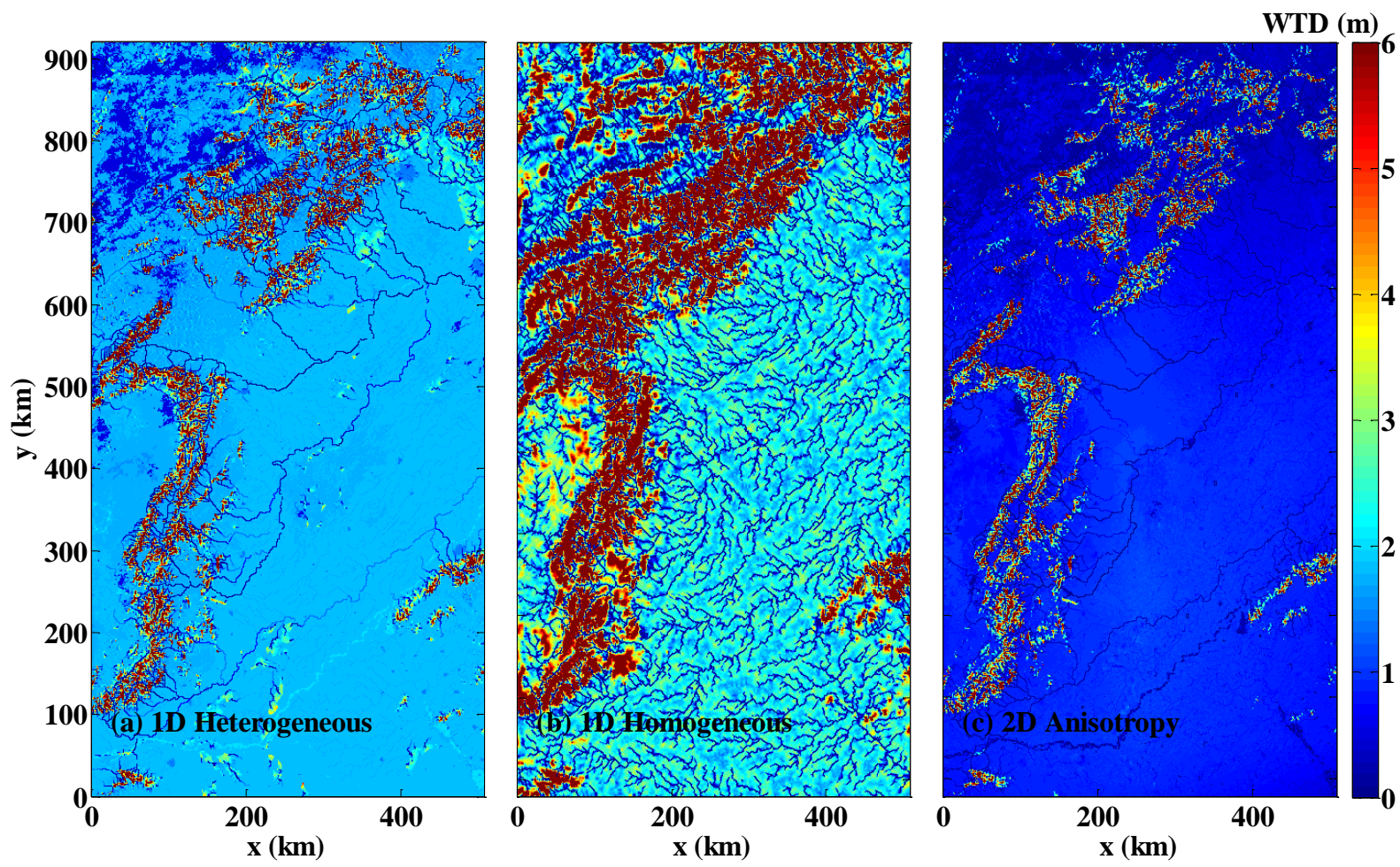

Figure S1. Simulated annual averaged water table depth (WTD) in the NCP for scenarios 3-5.
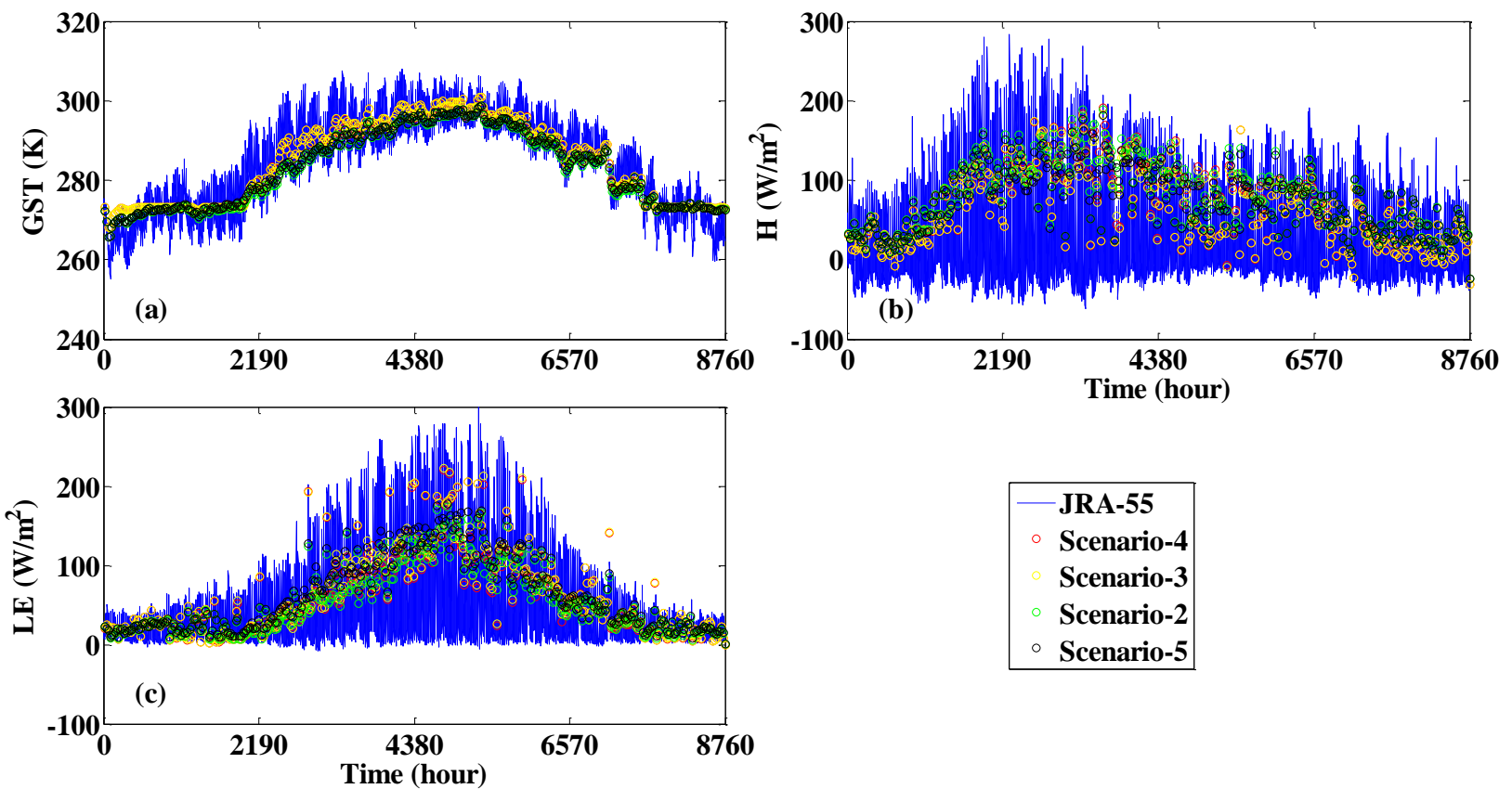

Figure S2. Spatially averaged variations of GST, H, and LE with time in 1970 for scenarios 2-5. 


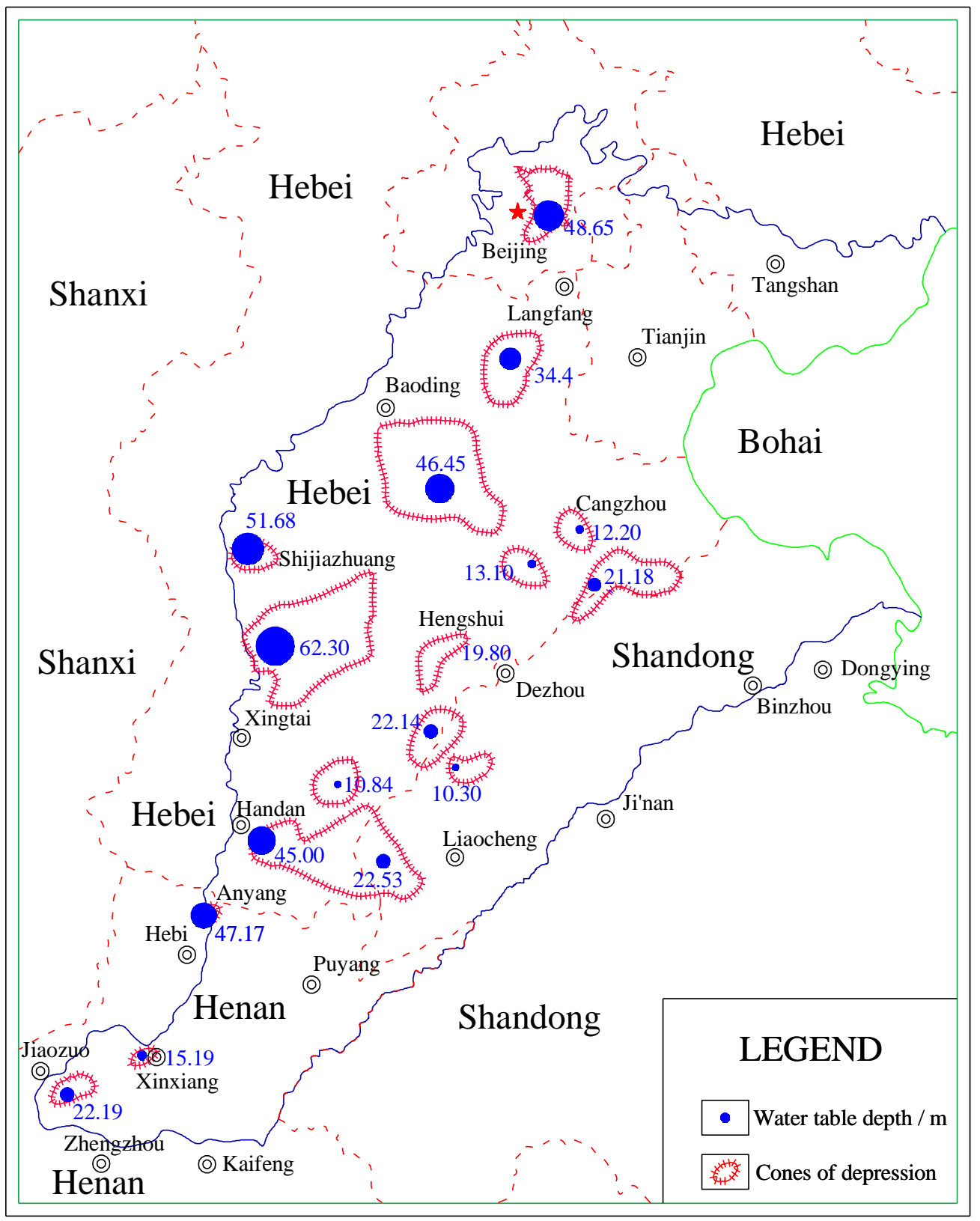

Figure S3. Cones of depression in shallow aquifers in the NCP [After $\mathrm{Li}$, 2013].

12 

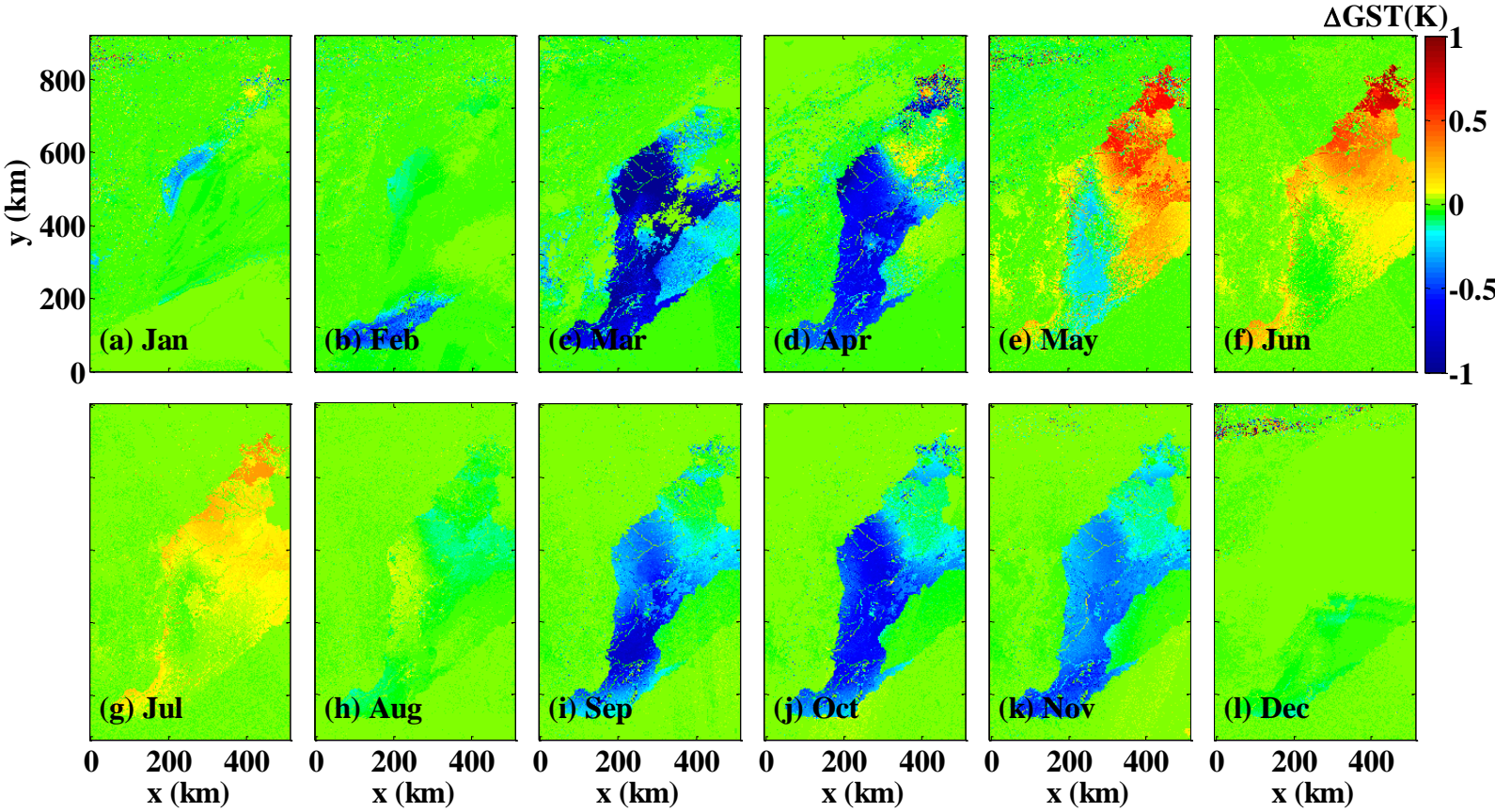

Figure S4. Simulated change of monthly averaged GST after two years of pumping.
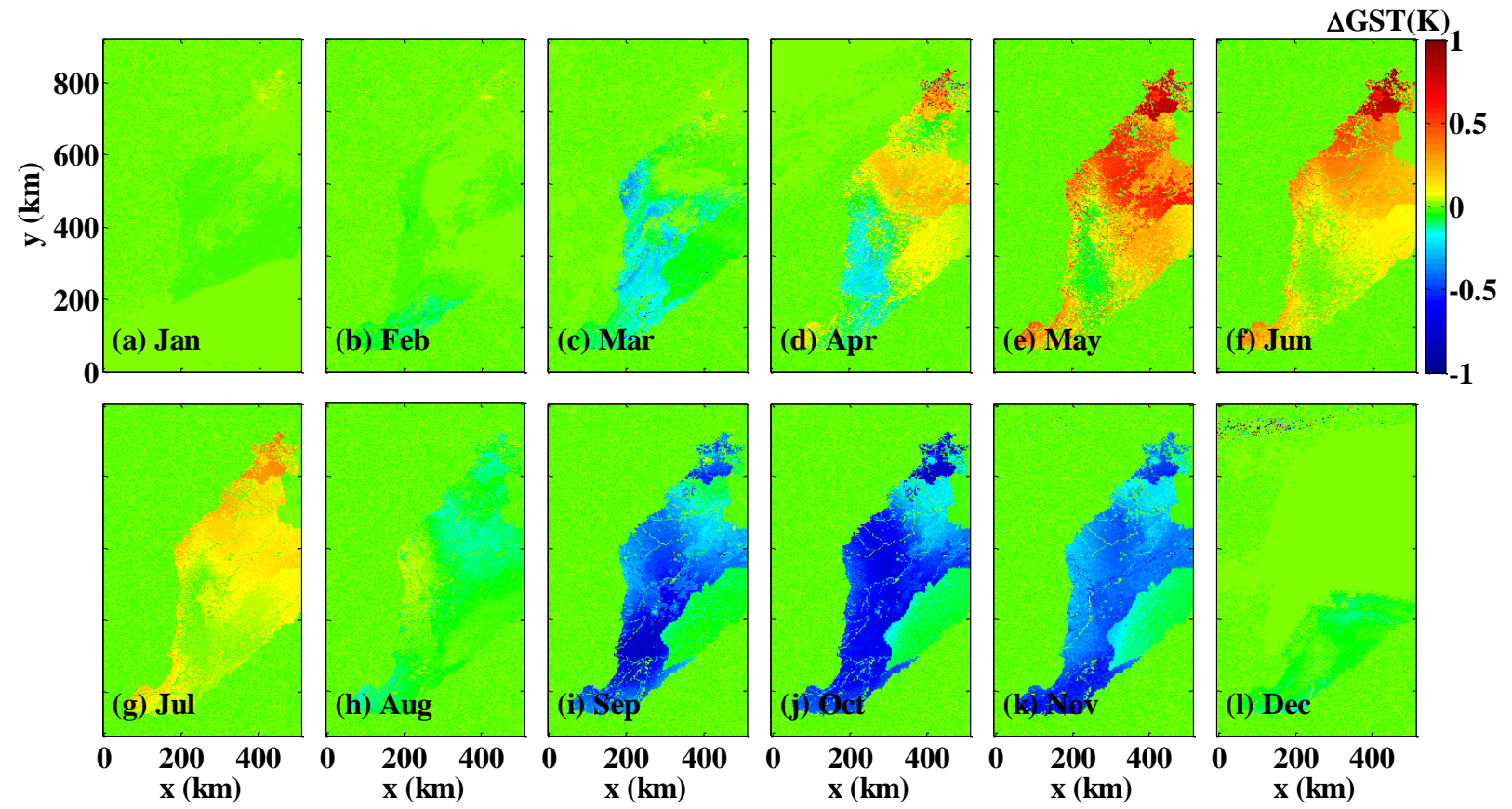

Figure S5. Simulated change of monthly averaged GST after one year of pumping with double pumping rate. 

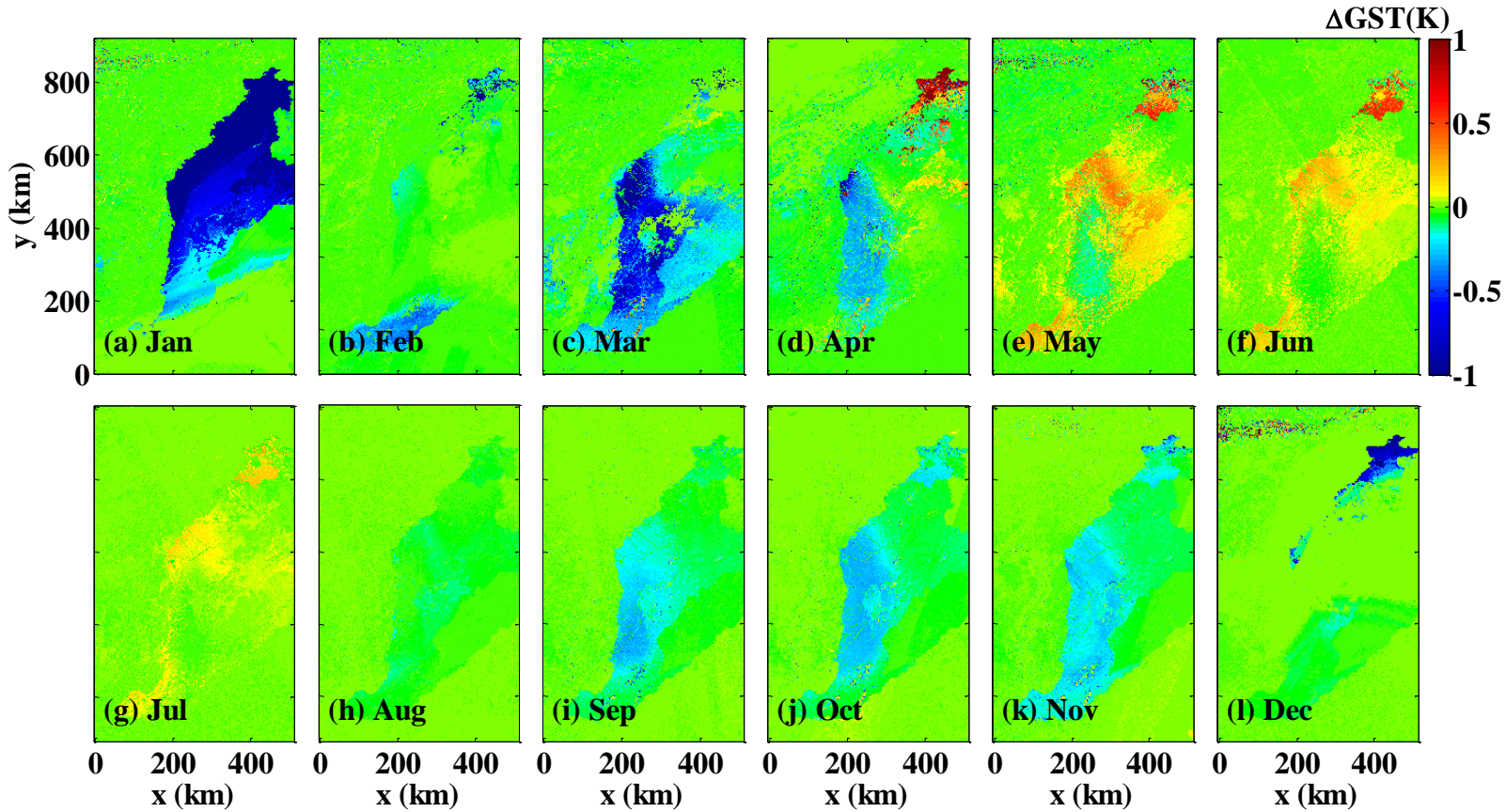

Figure S6. Simulated change of monthly averaged GST after two years of pumping and irrigation.
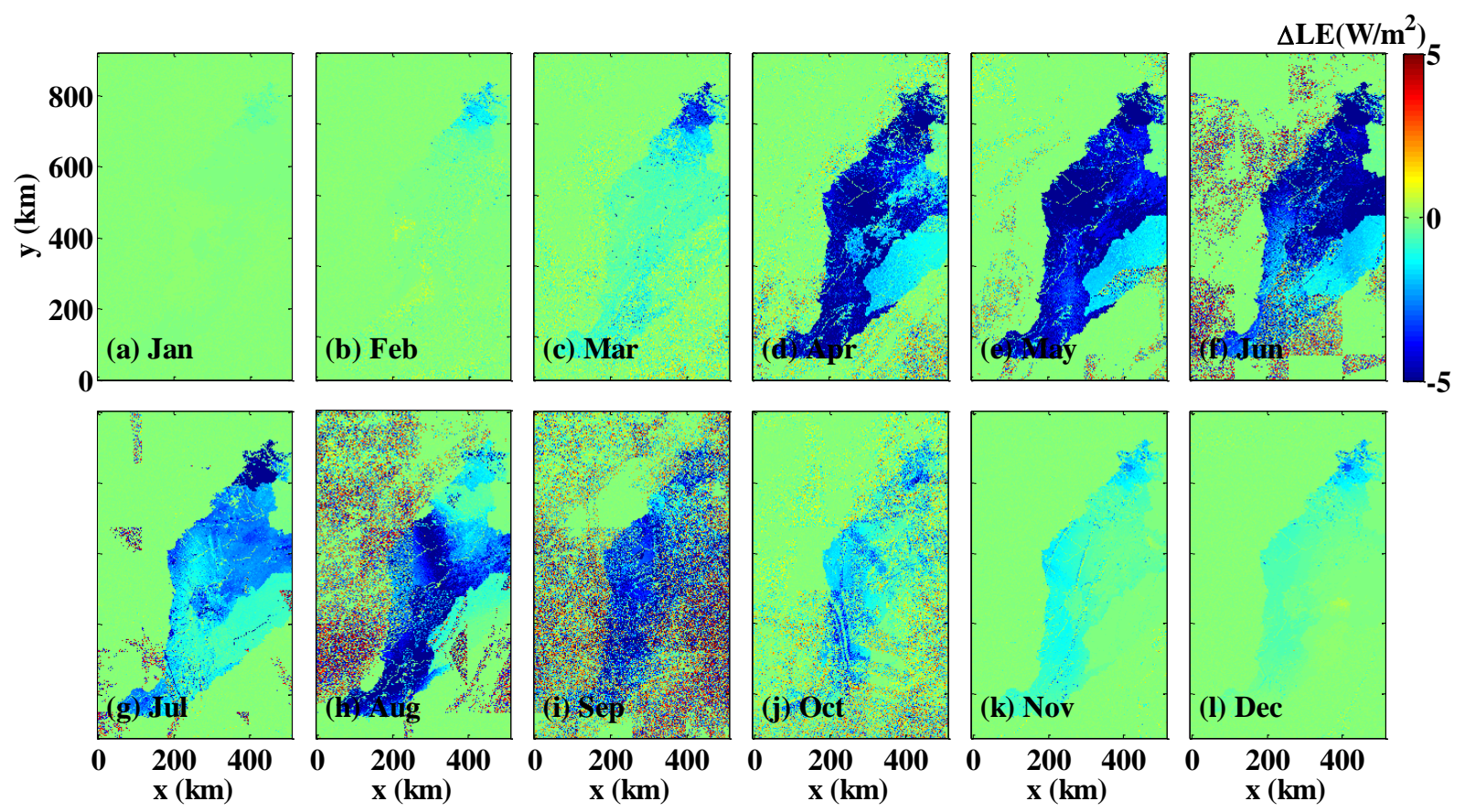

Figure S7. Simulated change of monthly averaged LE after one year of pumping. 


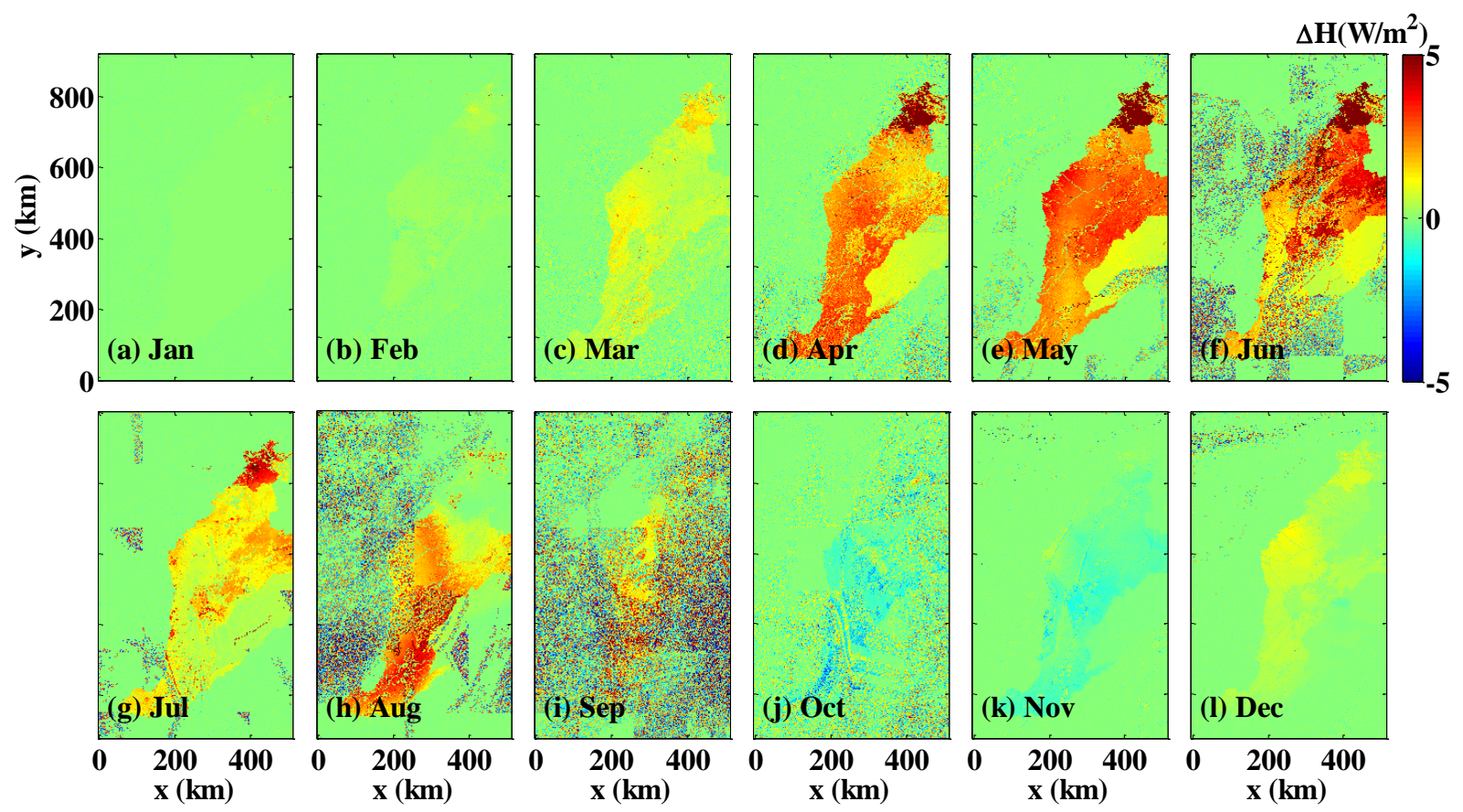

Figure S8. Simulated change of monthly averaged $H$ after one year of pumping. 